Cómo citar este artículo / How to cite this article: Benítez de Lugo Enrich, L., Rodríguez-Antón, A., Palomo Palomo, J. y Moraleda Sierra, J. (2021). Megalitismo y arqueoastronomía en la comarca de los Pedroches (Córdoba, Andalucía-España). Lucentum, XL, 9-28. https://doi.org/10.14198/ LVCENTVM. 17202

\title{
MEGALITISMO Y ARQUEOASTRONOMÍA EN LA COMARCA DE LOS PEDROCHES (CÓRDOBA, ANDALUCÍA-ESPAÑA)
}

\author{
MEGALITISM AND ARCHAEOASTRONOMY IN LOS PEDROCHES (CÓRDOBA, ANDALUSIA-SPAIN)
}

Recepción: 06/07/2020

Aceptación: 14/01/2021

\section{Resumen}

Los Pedroches es uno de los territorios andaluces más septentrionales, situado en el límite geográfico con Extremadura y Castilla-La Mancha. Sobre unos suelos poco aptos para el cultivo, pero muy favorables para la explotación ganadera, se encuentran una serie de manifestaciones megalíticas diseminadas, poco conocidas y apenas estudiadas. El estudio de las orientaciones de monumentos megalíticos puede aportar información acerca de las nociones del espacio, el tiempo o la muerte de las sociedades que los construyeron. Este trabajo presenta un avance del estudio arqueoastronómico de los dólmenes de Las Aguilillas, El Torno, Los Frailes, El Rongil y Torrubia, localizados en Villanueva de Córdoba. Los resultados obtenidos sugieren que el diseño y la ubicación de los megalitos incluidos en el presente estudio no es casual. Las orientaciones dadas a estos megalitos son, en general, compatibles con ortos solares o lunares y resultan consistentes con las orientaciones de conjuntos de sepulcros megalíticos en Andalucía y otras regiones de la península ibérica.

Palabras clave. Arqueología prehistórica; Calcolítico; túmulo; dolmen; península ibérica; prácticas funerarias.
LUIS BENÍTEZ DE LUGO ENRICH

Universidad Complutense de Madrid, España

luis.benitezdelugo@ucm.es

https://orcid.org/0000-0003-2000-6293

ANDREA RODRÍGUEZ-ANTÓN

Instituto de Ciencias del Patrimonio, Incipit-CSIC, España

andrea.rodriguez-anton@incipit.csic.es https://orcid.org/0000-0002-0786-3963

JUAN PALOMO PALOMO

sibulquez@gmail.com https://orcid.org/0000-0002-0199-484X

JAIME MORALEDA SIERRA

Anthropos S.L., España

anthropos@estudio-arqueologia.es https://orcid.org/0000-0003-1986-563X

\begin{abstract}
Los Pedroches is one of the most northern Andalusian territories, bordering on Extremadura and Castilla-La Mancha. A series of megalithic manifestations, little known and hardly studied, can be found on some soils unfit for cultivation but very favorable for livestock exploitation. The study of the orientations of megalithic monuments, together with further archaeological records, provides more information about the concept of time, space and the ideas of the death. This work presents an advance of the archaeoastronomical study of the dolmens of Las Aguilillas, El Torno, Los Frailes, El Rongil and Torrubia, located in Villanueva de Córdoba. The results obtained suggest that the design and the location of the megaliths included in this study are not accidental. The orientations given to these megaliths are consistent with the orientations of sets of megalithic sepulchers in Andalusia and other regions of the Iberian Peninsula.
\end{abstract}

Key words. Prehistoric Archaeology; Chalcolithic; barrow; dolmen; Iberian Peninsula; funerary practices. 


\section{INTRODUCCIÓN}

\subsection{ArqueOASTRONOMÍA Y MEGALITISMO}

A falta de otro tipo de fuentes, el análisis de la orientación de los monumentos funerarios megalíticos aporta una valiosa información a los estudios históricos sobre aspectos culturales de sus sociedades constructoras. $\mathrm{Su}$ localización y diseño dentro de un territorio configuran un paisaje cultural del que surgen conceptos de espacio y tiempo (Criado Boado, 1989) que podemos descifrar mediante el análisis de dichas configuraciones.

Se han podido identificar patrones de orientación en numerosos grupos de tumbas pertenecientes a una misma región en trabajos llevados a cabo en Europa Occidental (Hoskin, 2009; González-García y Belmonte, 2010; Ruggles, 2010), el Mediterráneo (Hoskin, 2001, Belmonte y Belmonte, 2002; Belmonte y Hoskin, 2002; Da Silva, 2004; Polcaro y Polcaro, 2006), la península ibérica (García y González García, 2009; González-García y Belmonte, 2010; Silva, 2013; Belmonte et al., 2017) o en regiones particulares de Andalucía (Hoskin, 1994; 1995a; 1995b) que sugieren la existencia de una relación entre su diseño y la posición de determinados astros, como el Sol y la Luna, en determinados momentos de sus ciclos.

En algunos lugares se ha observado cómo la orientación escogida permitía la entrada de la luz en la cámara de un dolmen, o en su corredor, en días particulares del año como equinoccios o solsticios. Ejemplo de orientaciones compatibles con la salida del Sol en los equinoccios se encuentran en el dolmen Zafra III en Valencia de Alcántara (Cáceres) (Belmonte et al., 2015) o en el dolmen de Viera en Antequera (Málaga), donde esos días la luz de Sol naciente ilumina todo el corredor de acceso.

Para poder adoptar la hipótesis astronómica, en general las orientaciones deben seguir un patrón definido dentro de un área extensa y dicha orientación no debe estar relacionada con la posición de algún elemento topográfico. También hay que descartar otros factores orográficos, como que todas las tumbas se encuentren sobre la misma ladera de una montaña mirando inevitablemente al mismo sector de horizonte, $\mathrm{y}$ factores ambientales como pueden ser vientos predominantes a nivel regional.

A partir de estos parámetros es posible realizar una aproximación arqueoastronómica al fenómeno megalítico de la comarca cordobesa de Los Pedroches.

\subsection{Los PEDROCHES}

Los Pedroches es un territorio cultural singular, poco conocido, situado al norte de Andalucía y plenamente identificable como comarca. Su patrimonio cultural denota, a través de diferentes épocas, el sentimiento de pertenencia a un territorio comarcal construido a lo largo de los tiempos y plenamente vigente en la actualidad. Cuenta con diecisiete poblaciones y $3612 \mathrm{~km}^{2}$.
La articulación de sus asentamientos, las relaciones socioeconómicas, simbólicas y políticas y su capacidad de constituirse en centro de atracción han contribuido a la construcción de este espacio supramunicipal de carácter comarcal periférico y alejado de los centros históricos del poder, en los límites más septentrionales de Andalucía y a caballo entre Extremadura y Castilla-La Mancha (Hernández, 2014).

Desde el punto de vista geográfico, la comarca de Los Pedroches, situada entre las estribaciones de Sierra Morena y la sierra de Santa Eufemia, es una penillanura (no un valle, como se la denomina habitualmente debido a la percepción de homogeneidad cultural) granítica suavemente ondulada, con materiales sedimentarios flanqueando el batolito al norte y sur con relieves más abruptos. El hecho de que se trata de un territorio de frontera se constata en las múltiples manifestaciones culturales de diferentes épocas que se proponen apropiar material y simbólicamente el espacio para construir un paisaje cultural en el que se percibe una personalidad específica.

El clima de la zona es mediterráneo con influencias continentales, debido a la cercanía de la Meseta, y oceánicos, llegados a través del valle del Guadalquivir. Consecuentemente, los inviernos son suaves y los veranos muy calurosos. Las precipitaciones oscilan entre 600 y $800 \mathrm{~mm}$ anuales, pudiendo llegar a los 1000 en algunas zonas del borde meridional de Los Pedroches.

Los suelos son mayoritariamente ácidos por ser silíceos, dominado los granitos, gneis, pizarras y grauvacas. Su desintegración produce alta frecuencia de arenas, siendo escasas las arcillas. La materia orgánica integrada en el sustrato es pobre, carente de los oligoelementos esenciales. Con frecuencia la aptitud agronómica es nula, debido al escaso desarrollo edáfico; con frecuencia los suelos carecen de horizonte estructural y simplemente existe un nivel superficial que directamente se apoya sobre la roca madre ácida (Valle, 1978; 1983; 2016; VV. AA., 2014).

Los factores bióticos (vegetación y fauna) son de gran valor. La vegetación es esclerófila, adaptada al clima de sequías estivales. Este territorio de amplias dehesas tiene una utilización ganadera indudable, preferentemente de ovino al oeste y porcino y vacuno al este. El valor y dinamismo de estos recursos le ha permitido superar con cierta dignidad las crisis económicas y regresiones demográficas que han azotado el campo español (Hernández, 1999; 2005).

\section{MEGALITISMO EN LOS PEDROCHES}

\subsection{ANTECEDENTES}

En la segunda década del siglo XX los extensos encinares de Los Pedroches eran fuente, no ya de riqueza, sino de subsistencia para poblaciones de la zona. En aquel momento se vieron asoladas por una plaga de orugas defoliadoras (Lymantria dispar). Para combatirla, el 
Servicio de Estudios y Extinción de Plagas Forestales instaló en marzo de 1921 una estación para el estudio de la defensa de estos encinares en Villanueva de Córdoba, centro geográfico de las dehesas del nordeste cordobés. El ingeniero de montes Manuel Aulló Costilla y el auxiliar de montes Ángel Riesgo Ordóñez fueron destinados a ella. En su actividad profesional obtuvieron un gran éxito, logrando eliminar esta plaga. Como prueba de agradecimiento, el pueblo de Villanueva de Córdoba nombró a ambos «Hijos Adoptivos» y le dio el nombre de «Manuel Aulló» a una nueva plaza de la población, en la sesión del Ayuntamiento del 24 de marzo de 1924.

Manuel Aulló era el ingeniero jefe, pero el encargado del trabajo de campo era Ángel Riesgo. Fue él quien recorrió el territorio «finca a finca y palmo a palmo; a pie y a caballo» (Riesgo, 1954) por los encinares de la suave penillanura del batolito, y el que se percató de los numerosísimos vestigios de las distintas culturas que a través de los tiempos habían habitado Los Pedroches y que «no habian sido nunca objeto de investigación seria por parte de las personas que, amantes de estos descubrimientos, pueden seguramente contribuir al conocimiento de la historia patria» (Aulló, 1925: 2). Aulló obtuvo autorización para efectuar excavaciones arqueológicas por Real Orden del 20 de septiembre de 1923, pero fue su auxiliar, Riesgo Ordóñez -quien conocía realmente el territorio- el que las llevara a cabo «aprovechando sus días de descanso y con un interés y un entusiasmo cuya medida no acertaré nunca a encomiar lo bastante» (Aulló, 1925: 4).

Riesgo dio cuenta en sus libretas de campo de 29 megalitos, dejando sin explorar solo cuatro de ellos, aunque prácticamente la mitad los encontró destrozados. Muchos de los objetos que halló en ellos le fueron robados al comienzo de la Guerra Civil, al sufrir un expolio su casa. Sus cuadernos de campo fueron rotos, pero pudieron ser recompuestos gracias a los fragmentos conservados y su memoria.

Entre el ingeniero Aulló (que firmaba pero no excavaba) y su auxiliar Riesgo (que excavaba y no firmaba) surgió un conflicto por la autoría de los trabajos.

Aulló (1925) publicó una memoria de las excavaciones, cuando llevaban 5 dólmenes excavados, lo que ocasionó un serio distanciamiento entre él y Riesgo, pues éste se consideró ninguneado. En sus memorias se queja amargamente y rebate «al Sr. Aulló la paternidad que quiso usurparme de estas excavaciones que toleré en un principio y no pude soportar luego» (Riesgo, 1954). Posteriormente publicó algunos artículos con sus trabajos (Riesgo, 1934a; 1934b; 1934c; 1934d; 1934e; 1934f; 1936a; 1936b; 1948).

Además de ellos, otros autores se han preocupado por el tema que nos ocupa.

También a partir de la década de 1920 el ingeniero de minas Antonio Carbonell Trillo-Figueroa comenzó a publicar diversos hallazgos de vestigios de épocas pasadas. Entre ellos figuran algunos referentes a yacimientos megalíticos, basándose sobre todo en la información que le transmitía Manuel Aulló, e incorporando algunos más descubiertos por él (Carbonell, 1927a; 1927b; 1928; 1946).

El primer estudio riguroso sobre el megalitismo en el noreste cordobés lo llevaron a cabo Georg y Vera Leisner (1943), recogiendo en su obra tanto las estructuras dolménicas como los ajuares funerarios a los que tuvieron acceso. La pareja Leisner tuvo conocimiento del megalitismo en Los Pedroches por la publicación de 1925 de Aulló pero, dado el alejamiento entre éste y Riesgo, el matrimonio alemán, de haber contado con el apoyo de Riesgo, verdadero conocedor del fenómeno en la zona, habría podido contribuir a aumentar el número de yacimientos citados por los Leisner. Algunos de los dólmenes citados por los Leisner son coincidentes con los citados por Riesgo, pero otros no figuran entre los hallados por éste.

En 1967 el cronista de Villanueva de Córdoba, Juan Ocaña Torrejón, publicó un artículo sobre «los túmulos de Los Pedroches», basándose fundamentalmente en los datos de la libreta de campo de Riesgo Ordóñez, y ofreciendo algunos nuevos a los descritos por él, aunque también se deslizó alguna confusión: Ocaña consideraba que el tholos del Minguillo descubierto por Riesgo (Minguillo I) y el excavado por Matías Moreno y los Leisner eran dos sepulcros diferentes, pero del estudio del cuaderno de campo de Riesgo se deduce claramente que son el mismo, como dedujo Marfil Lopera (1997a; 1997b) en sus estudios. También adaptó algunos datos, como los nombres de los propietarios de las fincas donde estaban los megalitos, a sus tiempos.

Basándose sobre todo en el trabajo de los Leisner, Cabrero (1985) catalogó y clasificó en su obra los dólmenes que había estudiado el matrimonio alemán a partir de sus descripciones. Estos trabajos versaban sobre los monumentos funerarios y los ajuares hallados en ellos, sin considerar para nada el poblamiento. Este aspecto fue abordado por vez primera por Murillo Redondo (1986). A este autor se debe el conocimiento y la descripción de los ídolos-falange hallados en el dolmen de El Atalayón (Murillo, 1988).

El trabajo de clasificación de los ajuares que aún se conservaban, y una puesta al día sobre la bibliografía y la información disponible sobre el megalitismo de Los Pedroches, fueron desarrollados por Marfil Lopera (1997b).

Aunque escasas, las manifestaciones artísticas de los megalitos de los Pedroches fueron dadas a conocer por Bueno Ramírez et. al. (2004).

En conjunto, estos autores citan 44 megalitos en el noreste de Córdoba. Con la excepción de un tholos descubierto por Riesgo en la zona del Minguillo (noreste de Villanueva de Córdoba) todos los megalitos conocidos en la comarca de Los Pedroches eran sepulcros de corredor o galería. En la década de 1980, y en la misma zona de El Minguillo, unas obras de construcción de un depósito en un promontorio sacaron a la luz otro sepulcro de planta circular y falsa cúpula: el tholos Minguillo IV (Martín de la Cruz y Gutiérrez, 2007). Destaca por su gran depósito ritual, como dos 
conjuntos de cuentas de collar de piedra pulimentada de 37 y 32 piezas, 127 puntas de flecha de muy variada tipología y 291 fragmentos cerámicos, incluyendo uno de un plato de borde almendrado con decoración incisa de tipo esteliforme. Es el depósito ritual más abundante de los conocidos en Los Pedroches; está expuesto en el museo de Villanueva de Córdoba.

También en la década de 1980 Antonio Fernández Fernández, uno de los dueños de la finca de Los Frailes (al sureste de Villanueva de Córdoba), nos llevó a ver una singular piedra enhiesta que había descubierto, a la que denominaba «el monolito». Pudimos constatar que se trataba de un menhir de granito rojo y faliforme levantado sobre la penillanura de las dehesas de Los Pedroches. Era el primero de este tipo que se conocía en Los Pedroches (Gutiérrez y Palomo, 2002).

Próximos al menhir existen tres megalitos, que no habían sido conocidos por los autores citados anteriormente. A los 44 citados por las fuentes bibliográficas hay que añadir otros 18 que se han conocido por el trabajo de campo. Estos megalitos complementan el conjunto de manifestaciones megalíticas conocidas y publicadas de la provincia de Córdoba (Marfil, 1997a; 1997b; Moreno y Carmona, 1992; Muñiz et al., 1993; Márquez, 2001; Martínez, 2002; Ibarra de Dios et al., 2003; Gavilán y Vera, 2004; Santos, 2007; Gavilán, 2009; Gutiérrez, 2010; Gavilán et al. 2013).

\subsection{Muestra}

Para el presente estudio se han seleccionado siete megalitos, en función de varias circunstancias.

La primera es la conservación hasta hoy de los mismos. Como exponía Ángel Riesgo en sus cuadernos de campo, «En los únicos túmulos que aún se conservan las cámaras funerarias, son el del Atalayón en finca de Francisco Doctor; el de las Aguilillas, finca de don Antonio Herruzo; el de las Navas, finca de Juan Coleto (a) Rísquez (hoy 1943 sí está derruido por completo); el del Torno, finca de don Francisco Ayllón. Estos se conservan porque sus enormes losas son dificiles de arrancar». Sobre el que nombra de las Navas, decía: «Año 1936, marzo. Según noticias de F. Díaz, fue deshecho este túmulo por Rísquez este año, para con sus piedras obtener grava para la carretera inmediata». En cuanto al del Atalayón, del que los Leisner dibujaron su estructura, se ha perdido por completo, conservando solo el túmulo de tierra. De otros solo podemos reconocer el túmulo, sin saber si están intactos o expoliados. Según se comprueba en el de las Aguilillas, esta destrucción dolménica puede remontarse a la Edad del Bronce.

La segunda circunstancia para la elección de la muestra es la variedad tipológica. El tipo más abundante en la comarca es el sepulcro de corredor, aunque

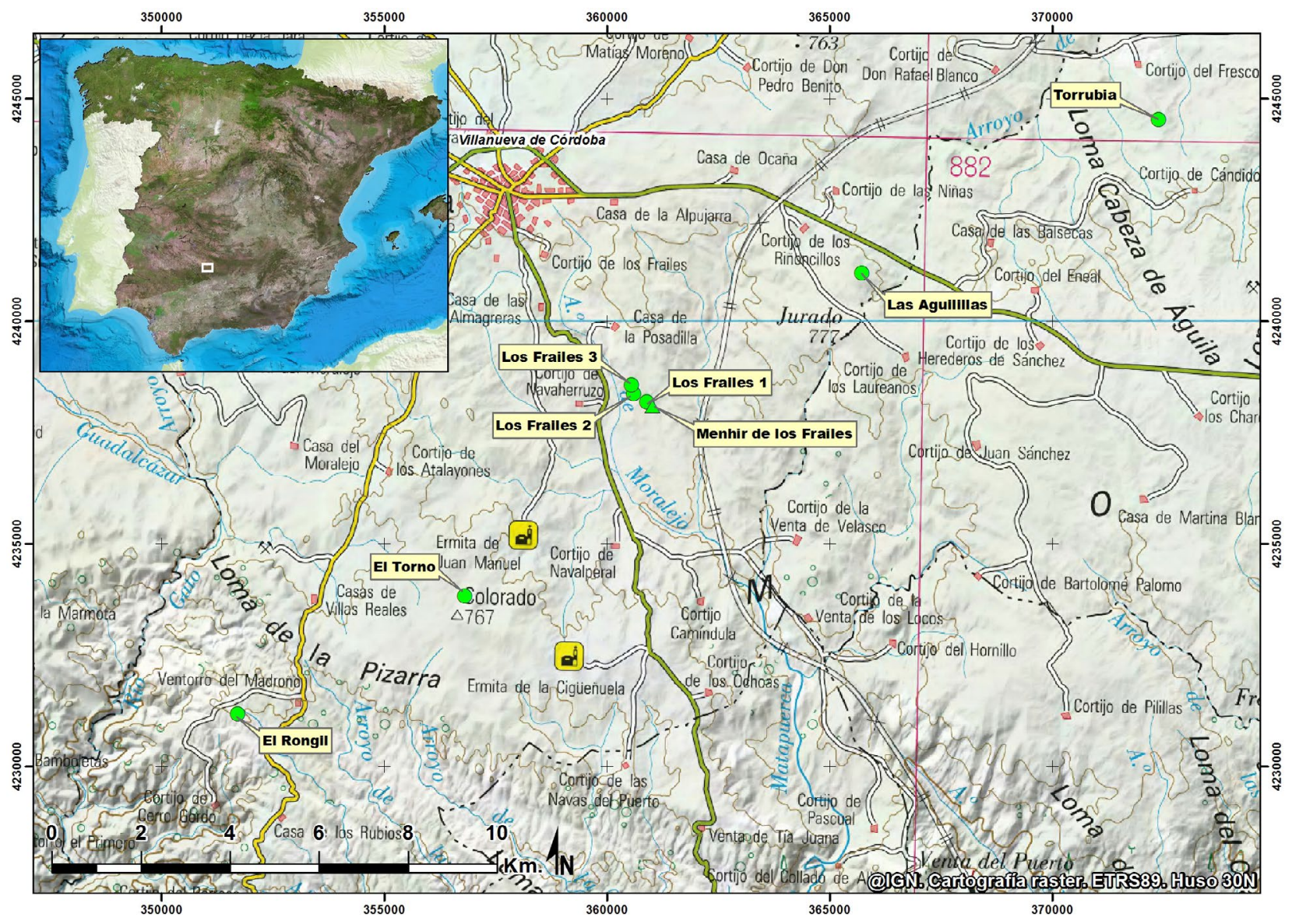

Figura 1: Localización de la zona de estudio y muestra investigada 
también los hay de tipo galería, y dos tholoi. El primero de este tipo, Minguillo I, fue descubierto por Riesgo en 1931. Fue «explorado» ese mismo año por el alcalde de Villanueva, Matías Moreno; vuelto a excavar por los Leisner; posteriormente, Riesgo volvió a buscar en él; por último, el encargado de la finca de la década de 1960 pasó muchas horas removiendo sus escombros. Con estas circunstancias es difícil incluso reconocerlo sobre el terreno.

La tercera es la concentración y variedad tipológica de sepulcros funerarios que hay en las proximidades de uno de los escasos menhires conocidos en Los Pedroches, en la zona de Los Frailes (Villanueva de Córdoba).

Con estos parámetros se han seleccionado como muestra de este estudio 7 dólmenes: en Torrubia (Cardeña), porque su orientación hacia el noreste es muy dispar de la usual; el de Las Aguilillas, por ser el más majestuoso de los conservados, y contar con información de su depósito ritual; el de El Torno, por sus pinturas esquemáticas, similares a las de Sierra Madrona (Ciudad Real) (Márquez Triguero, 1997; Fernández Rodríguez, 2003); el de El Rongil, por encontrarse fuera del batolito granítico que define Los Pedroches, donde se ubican la gran mayoría de los megalitos conocidos; y los tres de Los Frailes, por lo expuesto anteriormente (Fig. 1).

Como se ha expuesto, en general el estado de conservación no es muy bueno, en parte porque todos ellos se encuentran en fincas privadas y han sufrido durante siglos los efectos de sucesivas actividades agrícolas y ganaderas, así como expolios. Este hecho impide realizar una clasificación de las tumbas de acuerdo con el tipo de entorno en el que se ubican y la visibilidad de su horizonte. Por ello ha sido preciso poner más atención en obtener información a partir de las orientaciones y de su tipología.

\subsection{Dolmen de Las Aguilillas}

El nombre merece una aclaración, pues en la cartografía del Instituto Geográfico Nacional (MTN25) y en el 1:10.000 del Instituto de Estadística y Cartografía de Andalucía (IECA) aparece como «Las Anguilillas». Se trata de un error. El nombre del pago, Las Aguilillas, fue recogido correctamente por Patricio Bermudo Gutiérrez en su estudio sobre la evolución de la propiedad rústica privada en Villanueva de Córdoba a finales del siglo XVIII y en el siglo XIX. En su obra da a los predios los nombres que aparecen en los protocolos notariales, fuente de su estudio. De 186 fanegas (119,78 hectáreas) de cabida, en 1825 Las Aguilillas pasaron por herencia a María de los Dolores Martínez Moreno, esposa de Cayetano Herruzo (Bermudo, 1972), transmitiéndose hereditariamente en la familia Herruzo, poseedora del lugar en tiempos de Ángel Riesgo (año 1925) y en la actualidad. El nombre concreto del microtopónimo es «Peñón de las Aguilillas», por la enorme tapa del dolmen que permanece casi erguida, sobresaliendo varios metros.

El gran dolmen de Las Aguilillas fue visto por Riesgo tal y como se encuentra hoy: con su gran tapa inclinada y la cámara colmatada de tierra, sin vestigio alguno de túmulo que lo cubriera (Fig. 2). En sus libretas de campo Riesgo dice que tras limpiarlo encontró el ajuar funerario en una esquina del recinto. La información disponible parece indicar que dólmenes como éste pudieron ser saqueados o destruidos incluso en tiempos prehistóricos. El dolmen de La Fresnedilla, al sureste de Villanueva, también parece mostrar vestigios de su destrucción.

En Navalazarza, la finca colindante al oeste (ya en término de Cardeña), Riesgo da cuenta de la presencia de otro dolmen. A unos $2 \mathrm{~km}$ al sureste está el que Riesgo denominó Peñasco de Navalmaestre. El grupo megalítico (sepulcros y menhir) de los FrailesAlmagreras-Las Navas está a 5-6 km al suroeste.

En la misma finca de Las Aguilillas Ángel Riesgo localizó 67 sepulturas de época tardoantigua. Por el lugar discurría el Camino de la Plata, una antigua vía romana que se convirtió en el eje de comunicación más rápido durante el Reino de Toledo. Tras dejar de usarse en la Edad Media volvió a tomar relevancia en tiempos de los Reyes Católicos, convirtiéndose en la carrera oficial de Toledo y Madrid a Andalucía, hasta que Carlos III impuso el paso por Despeñaperros. Es decir, es una vía natural de comunicación que pudo emplearse desde tiempos remotos.

Sobre este dolmen Ángel Riesgo Ordóñez escribió lo siguiente en sus libretas de campo:

«TÚMULO DEL PEÑÓN DE LAS AGUILILLAS N ${ }^{\circ}$ 23

Septiembre de 1925.

Hállase enclavado este majestuoso túmulo en finca de don Antonio Herruzo, de Villanueva de Córdoba, excelente amigo, denominada Las Aguilillas, situado en lo más alto del cerro de las Aguilillas, con vista panorámica colosal, por el sur del $\mathrm{km} 63$ de la carretera Andújar - Villanueva, a unos $600 \mathrm{~m}$ de la carretera, en el borde de la meseta del cerro en el declive del norte y debajo de enorme peñón que se denomina «Peñón de las Aguilillas»; el cual peñón mide unos $5 \mathrm{~m}$ de largo, 4 de ancho y 1,5 de espesor, que yace como de hígado sobre rocas de granito, cual él, que afloran como límite de la misma meseta y del declive del terreno. En la parte sur de estas dos moles y completamente embutido en tierra, se halla la cámara sepulcral del túmulo, que mide unos $2 \times 3,5 x$ $1,5 \mathrm{~m}$ (ancho, largo y fondo). El gran peñasco pudo haber sido la cubierta del túmulo que con el tiempo se deslizó o basculó sobre el paramento del norte, pues no existen ni en el cortijo ni en las inmediaciones losas que fuesen de la cubierta del túmulo; pudo haber sido formada la cubierta en bóveda apoyada sobre el peñón.

El paramento norte de la cámara está formado por el peñasco que aflora del suelo donde descansa el peñón, y los paramentos del sur, este y oeste lo 

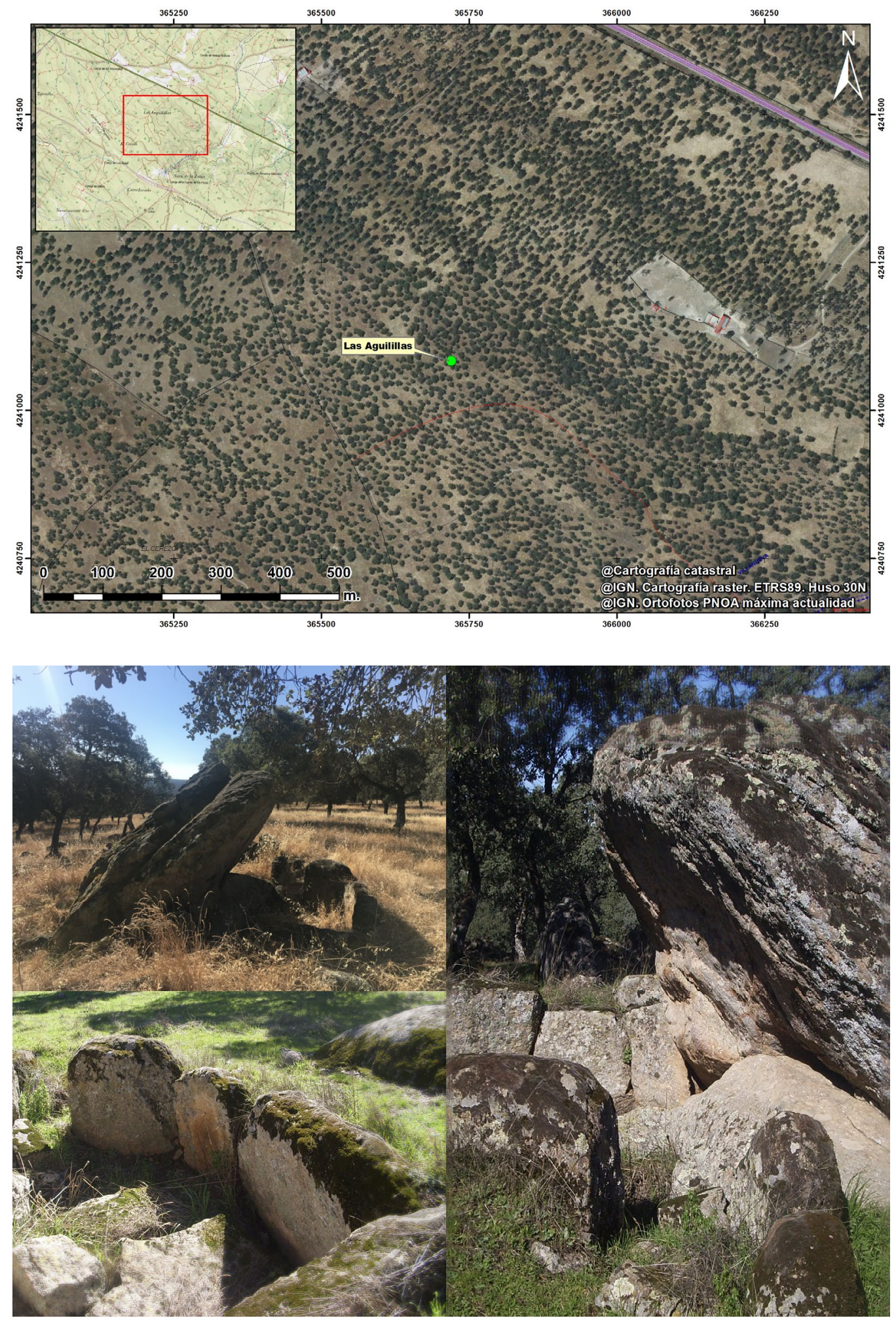

Figura 2: Dolmen de Las Aguilillas

constituyen grandes piedras colocadas verticalmente que en número de una y de dos cubren toda la superficie de estos paramentos.

La galería de entrada está asimismo formada por la roca que aflora por el norte. El paramento norte y el del sur lo forman recias piedras cual las de la cámara colocadas por mano del hombre. La salida se orienta al saliente.
A la derecha de esta galería, entrando, existe otra cámara sepulcral, aprovechando una piedra del paramento norte y otra roca que aflora más al norte, fuera de la cámara principal, y al parecer sin galería de entrada cual si fuese cámara descubierta para rellenar de tierra, quizá.

Fue hallado por mí este túmulo al iniciar las exploraciones de cistas en esta finca, al notar el rectángulo 
que aflorando a ras del suelo formaban las piedras de la cámara con el peñón.

La exploración, por el estado deplorable en que lo dejaron los buscadores de tesoros, hube de hacerla en varias veces, siempre fructiferas. Las tierras estaban en desorden completo, mezcladas con piedras de muy diferente tamaño; el fondo debió ser enlosado son varias piedras, las cuales fueron levantadas de su sitio por los profanadores del túmulo. El ajuar se halló en todos los horizontes y aun entre las piedras de los paramentos de la cámara.

Con relación a este importante túmulo y las cistas de esta zona y villares correspondientes, descubri, como prolongación del paramento norte de la cámara del túmulo, una recia cimentación, formadas por piedras de grandes dimensiones que se prolongan en línea recta en más de un kilómetro al este, a partir del oeste del túmulo, que cruzando esta finca pasa hasta la colindante de doña Sandalia Fernández, denominada Navalazarza. Otra cimentación igual, formando ángulo recto perfecto con ésta, parte del ángulo del oeste del túmulo, en dirección norte, como prolongación del paramento oeste de la cámara, alcanzando una longitud de unos $500 \mathrm{~m}$, perdiéndose en las inmediaciones de la carretera de Andújar Villanueva Km. 63. El cimiento parece prolongarse también hacia el oeste de dichos puntos, perdiéndose hacia la finca colindante de los hermanos Valero. Muy bien pudiera ser esta cimentación restos de reducto o muralla de protección de los villares existentes en aquella zona. Lo notable de esta muralla es que deja fuera de su recinto al túmulo a pesar de apoyarse en el paramento norte, que nos demuestra claramente que los habitantes de los villares de las Aguilillas y dueños de sus cistas no conocieron el túmulo o no estuvo relacionado con los constructores de la muralla, siendo también de notar que las cistas alli existentes eran de los tres tipos reseñados en las libretas de exploraciones de éstos, habiéndolos aquí de los reconstruidos, y hallando también tégulas romanas que nos pueden demostrar que esta cimentación pudo ser del último periodo de estos habitantes, los cuales habrían perdido ya la noción del túmulo dejando a éste fuera del recinto por ignorancia o por falta de aprecio.

Como hemos dicho el ajuar hallado estaba en completo desorden, hasta el extremo de que las vasijas halladas estaban juntas, unas dentro de otras en el ángulo del sudeste, y casi a flor de tierra, como

\begin{tabular}{|c|c|}
\hline Nombre & Las Aguilillas \\
\hline Término municipal & Villanueva de Córdoba \\
\hline Hoja & 881-41 1:10.000, IECA, Junta de Andalucía. \\
\hline Coordenadas XUTM & 365816 \\
\hline Coordenadas YUTM & 4241293 \\
\hline Descripción geográfica: & $\begin{array}{l}\text { Sito unos } 8 \mathrm{~km} \text { al este de Villanueva de Córdoba. Paisaje de dehesas cercadas sobre el } \\
\text { batolito granítico. El megalito se encuentra en el flanco este de una elevada meseta desde la } \\
\text { que hay una gran visibilidad hacia el norte. }\end{array}$ \\
\hline Morfología: & Meseta. \\
\hline Tipo & Dolmen de corredor con cámara rectangular. Tipo III.1 (Cabrero, 1985). \\
\hline Estructura & $\begin{array}{l}\text { Cámara rectangular de } 2,60 \mathrm{~m} \times 1,50 \mathrm{~m} \text {. Tres ortostatos forman el lado oeste, y cuatro } \\
\text { el paramento sur, el mejor conservado. En el interior de la cámara se encuentran los que } \\
\text { formaban la parte norte, apoyados sobre un afloramiento granítico. El pasillo se encuentra } \\
\text { muy deteriorado. Junto a él se construyó otra pequeña estructura tipo cista. La cubierta, de } \\
\text { unos } 5,5 \mathrm{~m} \times 4,5 \mathrm{~m} \times 1,5 \mathrm{~m} \text { y un peso de unas } 65 \mathrm{tm} \text { está inclinada } 45^{\circ} \text { sobre el lado norte. }\end{array}$ \\
\hline Materiales de industria lítica & $\begin{array}{l}64 \text { puntas de flecha (Marfil, 1997b: 52). } \\
30 \text { láminas de sílex (Marfil, 1997b: 53). }\end{array}$ \\
\hline Materiales de adorno & Sin documentar. \\
\hline Materiales varios & $\begin{array}{l}\text { Restos óseos humanos (un pequeño fragmento de cráneo y algunas coronas dentales, } \\
\text { depositadas en el Museo Arqueológico de Córdoba: Marfil, 1997b: 106). }\end{array}$ \\
\hline Materiales de piedra pulimentada & $\begin{array}{l}1 \text { hacha (Marfil, 1997b: 55). } \\
1 \text { azuela (Marfil, 1997b: 55). }\end{array}$ \\
\hline Materiales cerámicos & $\begin{array}{l}\text { - } 1 \text { urna funeraria decorada con ocho mamelones, atribuible al Bronce Pleno [27859]. } \\
\text { - } 6 \text { vasijas no decoradas } \\
\text { - } 1 \text { fragmento de borde. } \\
\end{array}$ \\
\hline Atribución cultural & Calcolítico. \\
\hline Estado de conservación & $\begin{array}{l}\text { Dañado, conservando bastantes ortostatos de la cámara y la gran tapa inclinada sobre ella. } \\
\text { La zona más alterada es la del corredor. }\end{array}$ \\
\hline Causas del deterioro & Furtivos. Labores agrícolas. \\
\hline Uso actual del terreno & Pastos/Monte bajo. \\
\hline Observaciones & $\begin{array}{l}\text { Uno de los escasos dólmenes descubierto por Riesgo Ordóñez que mantiene su estructura. } \\
\text { Es el más monumental de los conocidos en la comarca del tipo sepulcro de corredor. }\end{array}$ \\
\hline
\end{tabular}

Figura 3: Ficha de Las Aguilillas 
colocadas allí según el profanador fue hallándolas, dejándolas por objetos sin importancia. El ajuar consistia:

1 urna cineraria. $N^{o} 36$. De arcilla tosca siena, forma cilíndrica de cuerpo y fondo semiesférico, boca prolongación del cuerpo, parece torneada. Dimensiones: $24 \mathrm{~cm}$ altura, $76 \mathrm{~cm}$ perimetro cuerpo $221 / 2 \mathrm{~cm}$ diámetro boca. $N^{o} 36$ de mi colección. Rota por la boca.

1 cacerola [27859]. $N^{\circ} 32$. Arcilla negra fina, parece torneada, panza y fondo esférico; cuello cilíndrico, amplio, rebordeada la boca hacia afuera; presenta por debajo del cuello, casi en el centro de la panza, 8 mamelones en todo su perimetro. Dimensiones: 17,5 cm altura; $11 \mathrm{~cm}$ diámetro de la boca; $55 \mathrm{~cm}$ perímetro de panza. Desportillada por la boca

3 escudillas $N^{\circ} 33,34,35$. Arcilla negruzca, muy tosca, no torneadas y tosca forma; forma casquete esférico, de $6 \mathrm{~cm}$ de altura por $36 \mathrm{~cm}$ perímetro de la boca y $11 \mathrm{~cm}$ diámetro. Las $n^{\circ} 33$ y 35 las cedía don Manuel Aulló.

Se recogieron varios trozos que corresponden a otras tres escudillas de la misma forma semiesférica que se hallaron incompletas.

1 hacha en diorita plana, de 15,5 $\times 6 \mathrm{~cm}$.

39 puntas de flecha de varios pedernales, primorosamente talladas, dos de ellas en cristal de roca de varias dimensiones entre $1,5 \times 1 \mathrm{~cm}$ y $2 \times 3 \mathrm{~cm}$.

3 cuchillos de sílex de 12 a $16 \mathrm{~cm}$ largo por 1,5 a 2 cm ancho, obsequiados a don Manuel Aulló.

1 hacha en jaspe, plana, 7,5 $\times 3,75 \mathrm{~cm}$.

22 restos de cuchillos en sílex [27863, 28764 , $27865,27866,27867,27868,27869,27870,27871$, $27872,27873,27874,27875,27876,27877,27878$, 27933].

Varios restos informes de cerámica tosca, negra, neolitica.

Restos humanos consistentes en trozos informes, pequeños, en descomposición, muy triturados, por lo que no se recogieron más que

1 trozo de cráneo de forma elíptica, perfectamente recortado a juzgar por sus bordes, de $3 \mathrm{~cm}$ de largo por 2,50 cm ancho, curioso corte que parece producido por una trepanación.

Nota: Las referidas puntas de flecha desaparecieron de mi colección al ser saqueada mi casa por los rojos madrileños 1936».

La numeración entre corchetes a lo largo de la cita corresponde a la catalogación del Museo Arqueológico de Córdoba.

Sobre el estudio de los materiales encontrados por Riesgo puede consultarse los trabajos de Marfil Lopera (1997a; 1997b).

\subsection{Dolmen de El Torno}

Es otro de los dos encontrados por Riesgo que conserva su cámara. También lo descubrió como hoy está, con los ortostatos al aire (Fig. 6). Relevante en este dolmen es la pintura esquemática alada rojiza de su interior. Se trata de un motivo recurrente en los abrigos de Fuencaliente (Fig. 4), El Horcajo y Puertollano

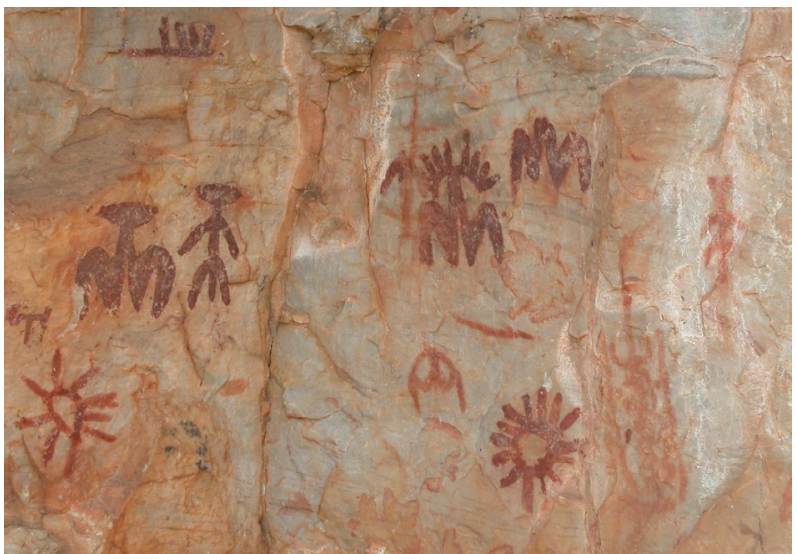

Figura 4: Soliformes en el abrigo de Peñaescrita (Fuencaliente, Ciudad Real)

(Ciudad Real) (Márquez, 1997; Fernández Rodríguez, 2003).

Esta zona sí es abundante en vestigios megalíticos. Riesgo cita ocho dólmenes (o restos tumulares) en las inmediaciones de El Torno:

- Atalayón de Navalmilano. Lo descubrió intacto bajo su cubierta tumular, aunque en la actualidad su cámara ha sido destruida por completo.

- 4 restos dolménicos o tumulares en la misma zona del Atalayón.

- Atalayuela.

- Torreznero.

- La Fresnedilla. Solo conserva tres ortostatos, pero por la distancia entre ellos $(4,30 \mathrm{~m}$ en el eje esteoeste) se deduce que sus dimensiones fueron las mayores de los conocidos en la comarca. Uno de sus ortostatos, decorado con cazoletas grabadas, se halla a unos treinta metros, lo que puede indicar una destrucción quizá en periodo prehistórico.

No hay constancia de minería antigua por el lugar. Parece reseñable la abundancia de fresnos, sin que haya un cauce fluvial, lo que indica que la capa freática es muy superficial y por tanto con gran capacidad agrícola.

Sobre el dolmen de El Torno escribía Ángel Riesgo en sus libretas:

\section{«TÚMULO DE EL TORNO No 10 \\ $F^{o}$ de la $1^{a}$ Libreta $n^{o} 35$ \\ 1 mayo 1923.}

1 túmulo. En finca asi denominada de D. Francisco Ayllón. De tradición se dice por el Valle, que esta finca o lugar se denomina «El Torno» por ser lugar de torneos o residencia de los reyes de Córdoba y especialmente se afirma que lo que es cámara funeraria del hermoso túmulo es lugar donde la «Reina Cava» martirizaba o sacrificaba a sus esclavos o prisioneros. En toda la finca no hallé restos de tales palacios, y sí sólo de algunos villares que exploraré, cual este túmulo (que actualmente, 1935, no pude hacer).

El promontorio de tierra y piedras a granel es irregular, de grandes dimensiones, mide más de 10 

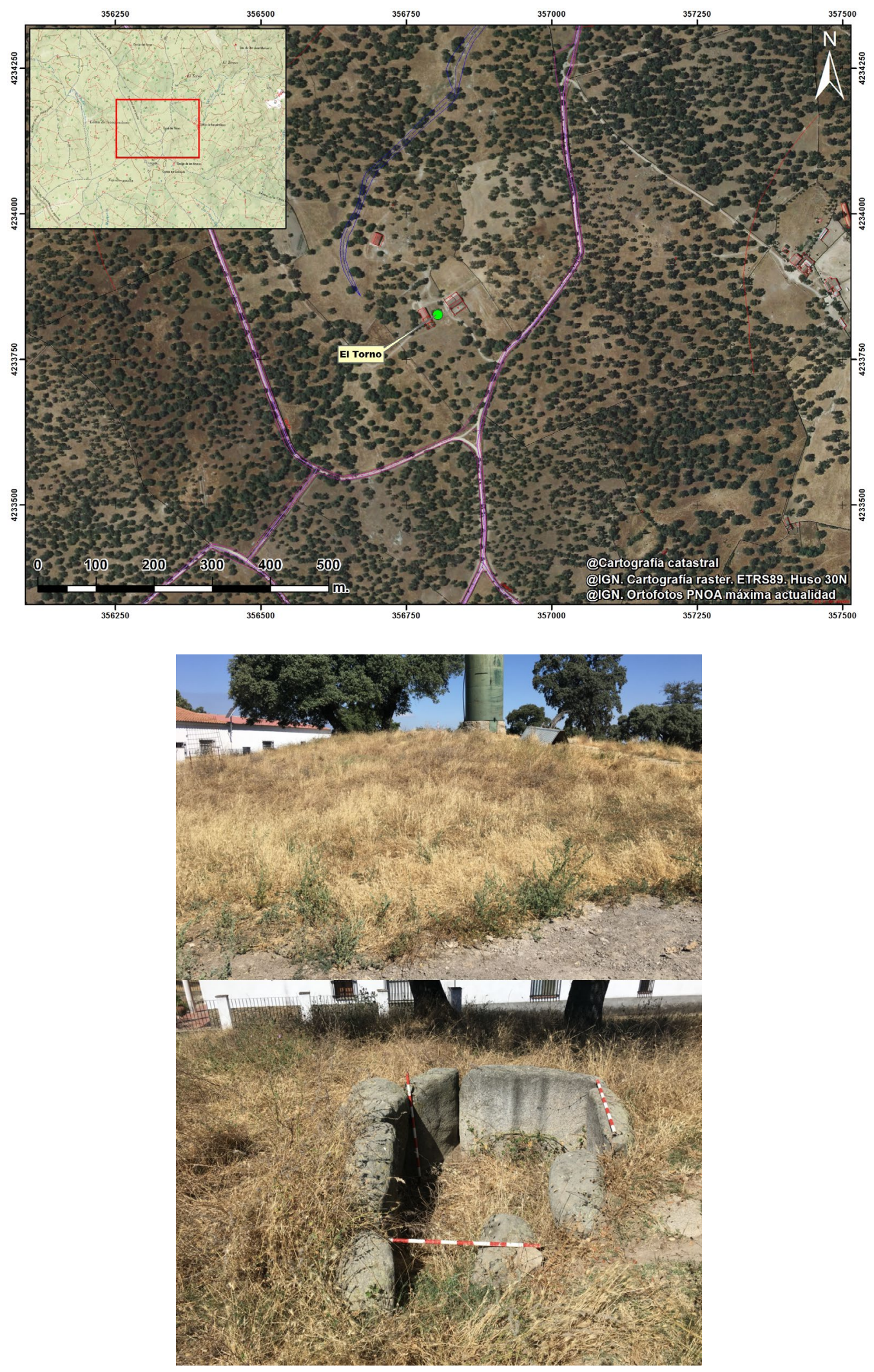

Figura 5: Dolmen de El Torno

$m$ de diámetro y la cámara $2 m$ de arista, forma rectangular, de recias piedras conservándose sólo las de tres paramentos formado cada uno de una sola losa bien cortada y gruesa; hallándose vacio hasta el fondo y sin cubierta. Fue explorado no obteniendo prenda alguna. Se halla situado en las inmediaciones del mismo cortijo». 


\begin{tabular}{|c|c|}
\hline Nombre & El Torno \\
\hline Término municipal & Villanueva de Córdoba \\
\hline Hoja & 881-32 1:10.000, IECA, Junta de Andalucía. \\
\hline Coordenadas XUTM & 356920 \\
\hline Coordenadas YUTM & 4234040 \\
\hline Descripción geográfica: & $\begin{array}{l}\text { Sito unos } 9 \mathrm{~km} \text { al sur de Villanueva de Córdoba. Paisaje de dehesas cercadas; substrato } \\
\text { granítico, conformando una penillanura de escaso relieve. }\end{array}$ \\
\hline Morfología: & Llano. \\
\hline Tipo & Dolmen de corredor con cámara rectangular. Tipo III.1 (Cabrero, 1985). \\
\hline Estructura & $\begin{array}{l}\text { Túmulo de unos } 10 \mathrm{~m} \text { de diámetro. Cámara rectangular de unos } 2 \mathrm{~m} \text { de arista compuesta } \\
\text { por } 7 \text { ortostatos, sobresaliendo en su lado oeste } 1,05 \mathrm{~m} \text { y disminuyendo su altura en el este. } \\
\text { Grosor de los ortostatos de } 0,40 \text { a } 0,25 \mathrm{~m} \text {. Corredor abierto al este. }\end{array}$ \\
\hline Materiales de industria lítica & 1 lasca retocada (Marfil, 1997b: 54). \\
\hline Materiales de adorno & Sin documentar. \\
\hline Materiales varios & Sin documentar. \\
\hline Materiales de piedra pulimentada & Sin documentar. \\
\hline Materiales cerámicos & $\begin{array}{l}2 \text { fragmentos de galbo y base de una vasija, con una serie de acanaladuras verticales } \\
\text { paralelas; } 1 \text { borde de cerámica no decorada; } 14 \text { fragmentos atípicos de cerámica no } \\
\text { decorada (Marfilb, 1997b: 58, 60-62). } 1 \text { fragmento con decoración plástica hallado entre las } \\
\text { raíces del fresno. }\end{array}$ \\
\hline Atribución cultural & Calcolítico. \\
\hline Estado de conservación & Dañado. \\
\hline Causas del deterioro & Furtivos. Labores agrícolas. \\
\hline Uso actual del terreno & Pastos/Monte bajo. \\
\hline Bibliografía y fuentes & $\begin{array}{l}\text { Leisner y Leisner (1943), Riesgo (1954), Ocaña (1967: 170-171, Cabrero (1985), Marfil } \\
\text { (1997b). }\end{array}$ \\
\hline Observaciones & $\begin{array}{l}\text { Es uno de los escasos dólmenes descubierto por Riesgo que mantiene su estructura. En el } \\
\text { paramento norte posee una pintura esquemática, y borrones indefinidos en el lado oeste. } \\
\text { Sobre la estructura tumular crecen dos encinas y un fresno, entre cuyas raíces había un } \\
\text { fragmento cerámico con mamelón perforado. }\end{array}$ \\
\hline
\end{tabular}

Figura 6: Ficha de El Torno

\subsection{Dólmenes de Los Frailes (I, II y III)}

En este paraje conocemos tres dólmenes y un menhir, ninguno de ellos detectado por Riesgo. Éste habla de otros seis dólmenes en la misma zona:

Almagreras I: También intacto cuando lo descubrió Riesgo en 1923. En 1936 fue machacado para obtener grava destinada a la carretera próxima que se estaba construyendo.

- Almagreras II.

- Navas I.

- Navas II y III: Están en la misma propiedad de los tres dólmenes y menhir conocidos, pero no hemos podido localizarlos aún.

- Navalmaestre.

Cabe reseñar que los tres sepulcros de Los Frailes, que presentan una interesante variedad tipológica, pues son una cista dolménica, un sepulcro de corredor y otro de tipo galería (Fig. 7). Se encuentran al oeste y en las cercanías de un menhir (Fig. 8). Solo tenemos conocimiento de este menhir y otro más en la comarca de Los Pedroches.

\subsection{EL RoNGIL}

Los Pedroches se caracterizan por estar surcados de noroeste a sureste por un batolito granítico delimitado a norte y sur por materiales sedimentarios. La gran mayoría de testimonios megalíticos se encuentran sobre este batolito. Fuera de la norma general, este sepulcro se encuentra un par de kilómetros al sur del batolito, aunque sus constructores aprovecharon un dique de materiales ígneos que se adentró entre las pizarras y grauvacas del Carbonífero (Fig. 12).

La pareja Leisner nombra un megalito en esta zona de La Pizarra, aunque no sabemos si se trata en concreto de éste. Una característica a destacar en él es que se trata de una galería dolménica, forma poco frecuente en la comarca.

\subsection{TORRUBIA}

En la parte septentrional de Los Pedroches, entre Conquista y Azuel, se encuentra este sepulcro de corredor en el pago de Torrubia. Su túmulo destaca sobre el paisaje, sobre todo visto desde su cara 

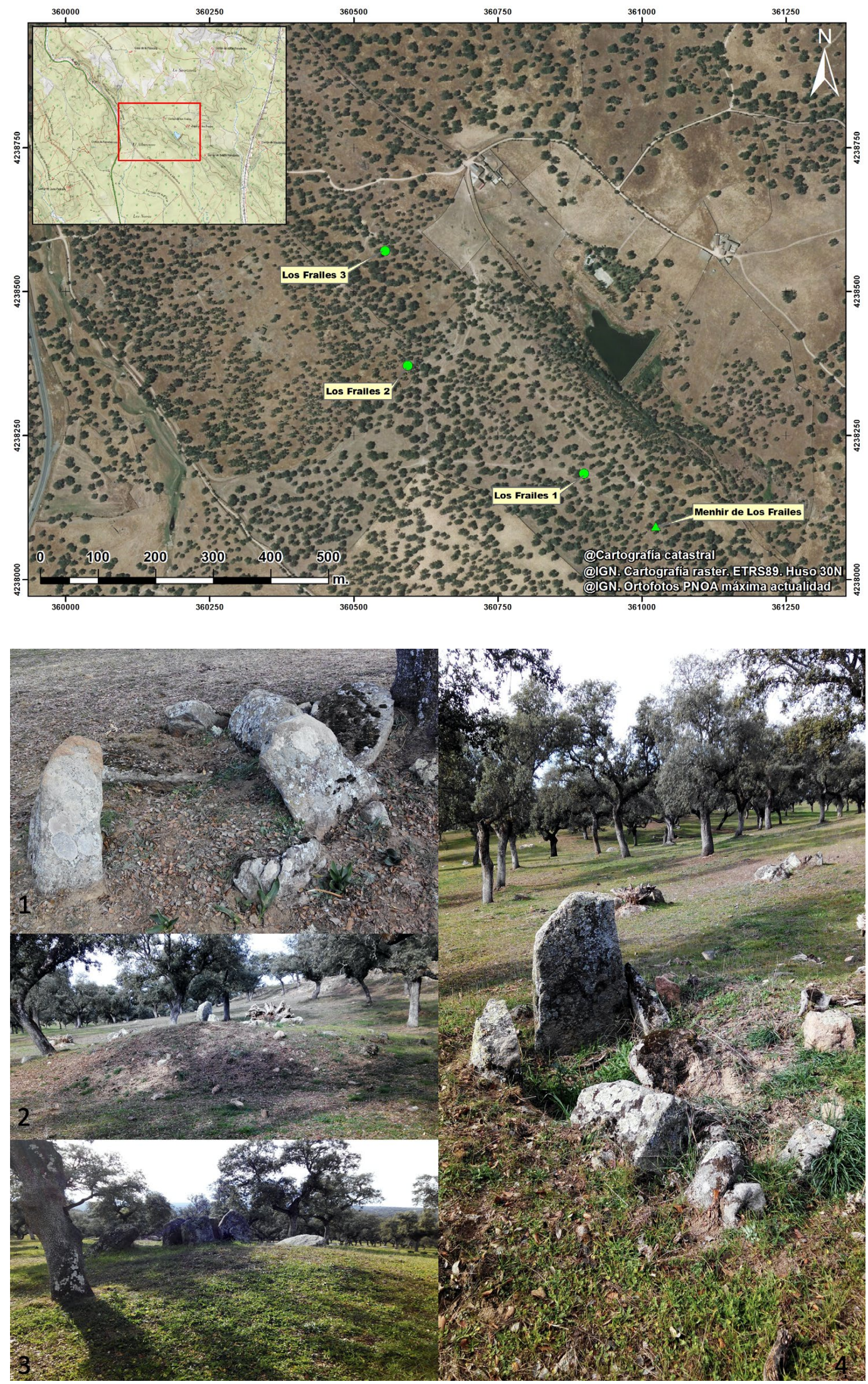

Figura 7: Localización de los dólmenes de Los Frailes. 1: Los Frailes 1; 2 y 4: Los Frailes 2; 3: Los Frailes 3 


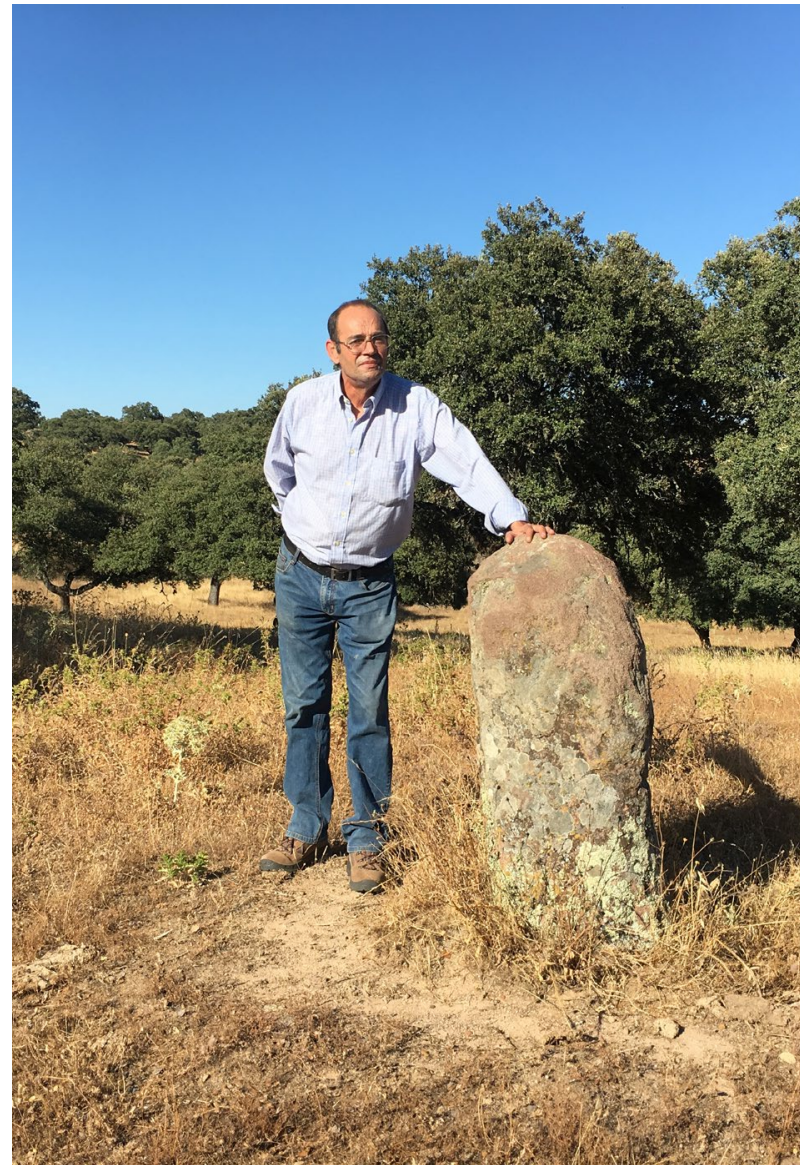

Figura 8: Menhir de Los Frailes sur. Su cámara es de dimensiones reducidas, y cabe señalar que su orientación no es al saliente, sino claramente hacia el noreste; a las cumbres de Sierra Madrona, lugar conocido por sus abundantes pinturas esquemáticas.

A un par de kilómetros al oeste se encuentran los dos tholoi de El Minguillo.

\section{ARQUEOASTRONOMÍA EN LA COMARCA DE LOS PEDROCHES}

\subsection{MÉtodo DE TRABAJO Y MUESTRA DE DATOS}

Los datos se tomaron in situ durante una campaña de trabajo de campo en julio de 2018. Para realizar las medidas se ha utilizado un tándem que cuenta con una brújula de precisión para medir el acimut (A), o ángulo respecto al norte geográfico, y un clinómetro para obtener la altura angular del horizonte (h). Estos instrumentos introducen errores nominales de $0,25^{\circ}$ en acimut y $0,5^{\circ}$ en altura. Para establecer el acimut, la medida de la brújula ha de ser corregida, pues el norte magnético no coincide con el norte geográfico. Para obtener el valor de la declinación magnética en el lugar y momento en que se realizaron las medidas, se ha utilizado el modelo de magnetismo terrestre más reciente de la NOAA (National Oceanic and Atmospheric Administration): https://www.ngdc.noaa.gov/geomag/ calculators/magcalc.shtml\#igrfwmm. El acimut de

\begin{tabular}{|l|l|}
\hline Nombre & Los Frailes I. \\
\hline Término municipal & Villanueva de Córdoba \\
\hline Hoja & $881-421: 10.000$, IECA, Junta de Andalucía. \\
\hline Coordenadas UTM & 361030 \\
\hline Coordenadas YUTM & 4238380 \\
\hline Descripción geográfica & $\begin{array}{l}\text { Sito unos } 5 \mathrm{~km} \text { al sureste de Villanueva de Córdoba. Paisaje de dehesas cercadas. La orografía } \\
\text { es ligeramente accidentada, por lo que recibe también el nombre de Sierrezuela. Abundantes } \\
\text { afloramientos de granito y cuarzo, sobre todo al norte. Visibilidad al sur desde el yacimiento. }\end{array}$ \\
\hline Morfología & Llano. \\
\hline Tipo & Cista megalítica. Tipo I (Cabrero, 1985). \\
\hline Estructura & $\begin{array}{l}\text { El dolmen está totalmente desmantelado, quedando de él siete pequeños ortostatos de los que aún } \\
\text { quedan dos hincados en el suelo, sobresaliendo uno 0,55 m y 0,75 m el otro, formando lo que } \\
\text { sería el paramento sur. Cámara orientada al este. }\end{array}$ \\
\hline Depósito ritual & Sin determinar. \\
\hline Atribución cultural & Calcolítico. \\
\hline Estado de conservación & Destruido en gran parte. \\
\hline Causas del deterioro & Furtivos. Labores agrícolas. \\
\hline Uso actual del terreno & Pastos/Monte bajo. \\
\hline Observaciones & $\begin{array}{l}\text { No consta en los cuadernos de campo de Riesgo. } \\
\text { Se encuentra a un centenar de metros del Menhir de los Frailes, y a unos centenares de metros de } \\
\text { los dólmenes de los Frailes II-III. } \\
\text { En lo que fue la cámara yace el más grande de sus ortostatos, pudiendo ser parte de la cubierta. } \\
\text { Casi carece de infraestructura tumular. } \\
\text { Cerca crece una encina, al albur del hueco creado. }\end{array}$ \\
\hline
\end{tabular}

Figura 9: Ficha de Los Frailes I 


\begin{tabular}{|l|l|}
\hline Nombre & Los Frailes II. \\
\hline Término municipal & Villanueva de Córdoba \\
\hline Hoja & $881-421: 10.000$, IECA, Junta de Andalucía. \\
\hline Coordenadas XUTM & 360710 \\
\hline Coordenadas YUTM & 4238580 \\
\hline Descripción geográfica & $\begin{array}{l}\text { Sito unos } 5 \mathrm{~km} \text { al sureste de Villanueva de Córdoba. Paisaje de dehesas cercadas. Abundantes } \\
\text { afloramientos de granito al norte, con relieve un tanto abrupto. Gran visibilidad al sur. }\end{array}$ \\
\hline Morfología & Vertiente. \\
\hline Tipo & Dolmen de corredor con cámara rectangular. Tipo III.1 (Cabrero, 1985). \\
\hline Estructura & $\begin{array}{l}\text { Posee estructura tumular de } 8 \text { m de diámetro, y en su cima afloran cuatro ortostatos que } \\
\text { conformarían la cámara rectangular de 1,3 x 0,93 m orientada al este. El paramento oeste está } \\
\text { formado por una sola pieza que aflora de la superficie 0,82 m. Posee un pasillo o corredor sin } \\
\text { excavar de 2,50 m de longitud. }\end{array}$ \\
\hline Depósito ritual & Sin determinar. \\
\hline Atribución cultural & Calcolítico. \\
\hline Estado de conservación & Destruido en gran parte. \\
\hline Causas del deterioro & Furtivos. Labores agrícolas. \\
\hline Uso actual del terreno & Pastos/Monte bajo. \\
\hline Observaciones & $\begin{array}{l}\text { No consta en los cuadernos de campo de Riesgo. Abundantes vestigios megalíticos en la zona: } \\
\text { se encuentra a unos 500 m del Menhir de los Frailes, unos 400 m de los Frailes I y 150 m de los } \\
\text { Frailes III. }\end{array}$ \\
\hline
\end{tabular}

Figura 10: Ficha de Los Frailes II

\begin{tabular}{|l|l|}
\hline Nombre & Los Frailes III. \\
\hline Término municipal & Villanueva de Córdoba \\
\hline Hoja & $881-421: 10.000$, IECA, Junta de Andalucía. \\
\hline XUTM & 360560 \\
\hline YUTM & 4238570 \\
\hline Descripción geográfica & $\begin{array}{l}\text { Sito unos } 5 \mathrm{~km} \text { al sureste de Villanueva de Córdoba. Paisaje de dehesas cercadas, con relieve un } \\
\text { tanto abrupto al norte del dolmen. Abundantes afloramientos de granito al norte. Se encuentra } \\
\text { sobre una pequena loma característica del paisaje del batolito de los Pedroches, con gran } \\
\text { visibilidad al sur, oeste y este. }\end{array}$ \\
\hline Morfología & Vertiente. \\
\hline Tipo & Dolmen de galería cubierta Tipo II.1 (Cabrero, 1985). \\
\hline Estructura & $\begin{array}{l}\text { Posee estructura tumular de 5 m de diámetro. Consta lo que se conserva del dolmen de 5 } \\
\text { ortostatos hincados en el suelo, tres en la parte sur que sobresalen del terreno 0,7 m y dos en el } \\
\text { paramento norte que sobresalen 0,74 m, de hasta 0,35 m de grosor. En la parte oeste yace una } \\
\text { piedra trapezoidal recostada que mide 1,15 m de alto por 1,14 m en su parte ancha y 0,71 m en } \\
\text { su base. Longitud desde el primer ortostato del este a la piedra recostada del oeste 3,90 m. }\end{array}$ \\
\hline Depósito ritual & Sin determinar. \\
\hline Atribución cultural & Calcolítico. \\
\hline Estado de conservación & Destruido en gran parte. \\
\hline Causas del deterioro & Furtivos. Labores agrícolas. \\
\hline Uso actual del terreno & Pastos/Monte bajo. \\
\hline Bibliografía y fuentes & Cabrero (1985), Riesgo (1954). \\
\hline Observaciones & $\begin{array}{l}\text { No consta en los cuadernos de campo de Riesgo. En esta zona hay numerosos vestigios } \\
\text { megalíticos: se encuentra a próximo al Menhir de los Frailes y los dólmenes de los Frailes I, y II. }\end{array}$ \\
\hline
\end{tabular}

Figura 11: Ficha de Los Frailes III

un dolmen se ha definido en este caso como el eje de la construcción, de dentro hacia fuera. Teniendo en cuenta que no siempre presentan una simetría clara y el mencionado estado de deterioro, se ha determinado la dirección desde el fondo de la cámara al centro del acceso a ésta, o bien se ha medido la orientación siguiendo la línea del corredor en aquellos que presentan esta estructura; de nuevo de dentro afuera.

La coordenada de altura angular del horizonte es necesaria para comparar la orientación con la posición 

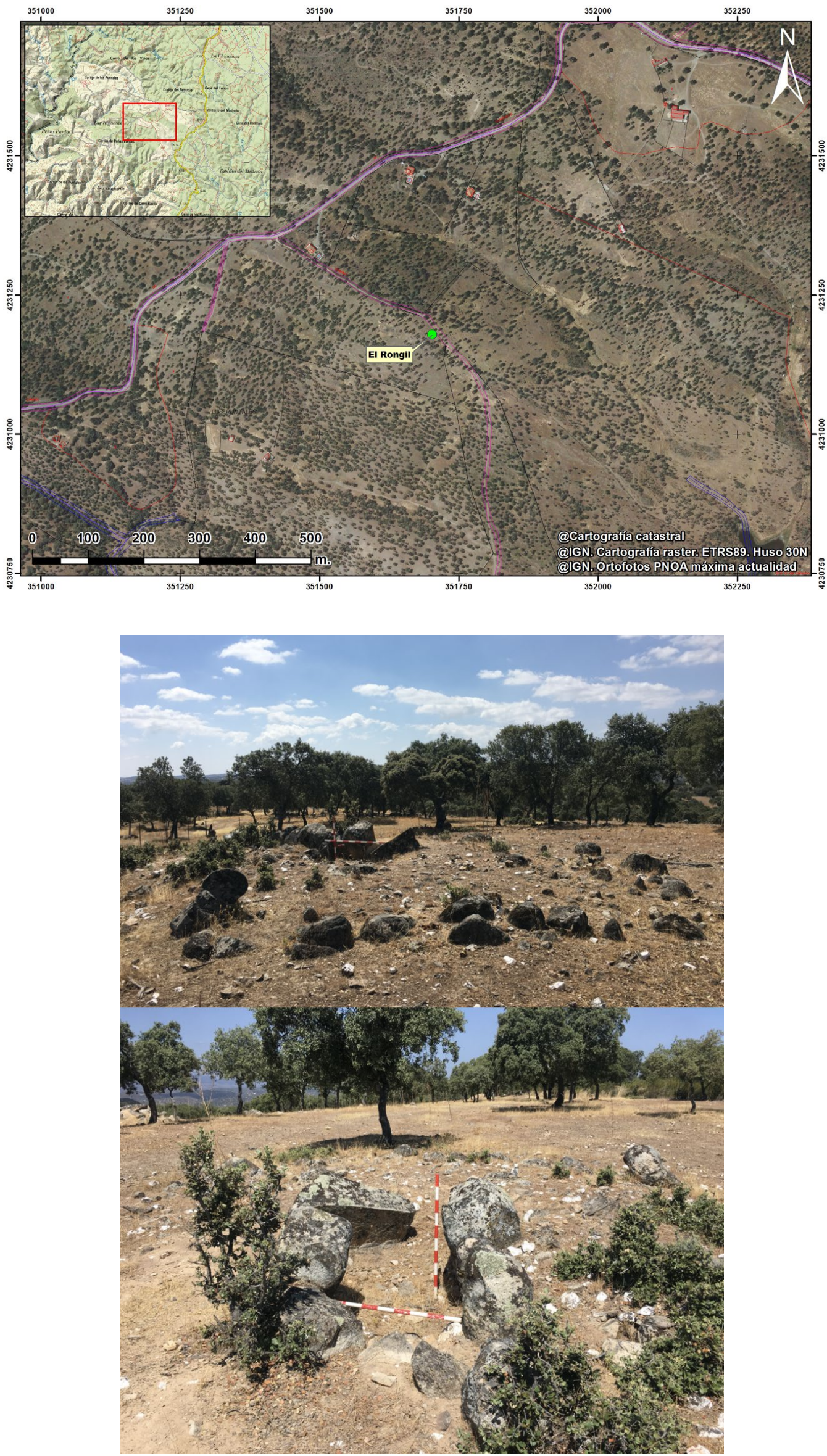

Figura 12: El Rongil. Vista general (arriba y detalle (abajo) 


\begin{tabular}{|l|l|}
\hline Nombre & Rongil \\
\hline Hoja & $881-231: 10.000$, IECA, Junta de Andalucía. \\
\hline Coordenadas XUTM & 351810 \\
\hline Coordenadas YUTM & 4231385 \\
\hline Descripción geográfica: & $\begin{array}{l}\text { Sito unos } 9 \mathrm{~km} \text { al sur de Villanueva de Córdoba. Paisaje de dehesas cercadas; penillanura de } \\
\text { escaso relieve, con abundantes afloramientos graníticos. }\end{array}$ \\
\hline Morfología: & Llano. \\
\hline Tipo & Dolmen de galería cubierta Tipo II.1 (Cabrero, 1985). \\
\hline Estructura & $\begin{array}{l}\text { Túmulo de unos } 8 \text { m de diámetro. El dolmen está destruido completamente, pudiéndose observar } \\
\text { en parte algunas piedras hincadas que formaron el contrafuerte del túmulo. Cámara posiblemente } \\
\text { rectangular. }\end{array}$ \\
\hline Depósito ritual & Sin documentar. \\
\hline Atribución cultural & Calcolítico. \\
\hline Estado de conservación & Destruido en gran parte. \\
\hline Causas del deterioro & Obras. Labores agrícolas. \\
\hline Uso actual del terreno & Pastos/Monte bajo. \\
\hline Observaciones & $\begin{array}{l}\text { No aparece citado en los cuadernos de campo de Riesgo, aunque quizá fuera conocido por los } \\
\text { Leisner. Destaca por su situación fuera de los límites del batolito de los Pedroches. }\end{array}$ \\
\hline
\end{tabular}

Figura 13: Ficha de El Rongil

real de un cuerpo celeste, pues la configuración del terreno afecta a la visibilidad de un astro desde un punto de observación. Para incorporar el factor del relieve a los datos recogidos se calcula una coordenada astronómica: la declinación $(\delta)$. La declinación depende del acimut (A), la altura del horizonte (h) y la latitud del lugar $(\varphi)$ y su valor no depende del punto de la Tierra en el que se encuentra el observador.

$$
\sin \delta=\sinh \sin \varphi+\operatorname{conh} \cos \varphi \cos \mathrm{A}
$$

Se ha escogido un valor conservador para el error en declinación de $\pm 1,5^{\circ}$, derivado del proceso de medición y considerando el estado de conservación de los monumentos. La declinación del Sol en los equinoccios es $0^{\circ}$, cuando el Sol cruza el ecuador celeste, y en los solsticios era de $\pm 24^{\circ}$ en el 3000 a. C. y de $\pm 23,5^{\circ}$ en el 1500 a. C. En el hemisferio norte, el valor positivo se corresponde con el solsticio de verano y el negativo con el de invierno, y ambos representan los valores máximo y mínimo de la declinación del Sol a lo largo de un año. Puesto que se desconoce la datación exacta de estos dólmenes, no es posible establecer el valor solsticial de declinación en la época en que fueron construidos. A falta de más datos se podría considerar, con bastante cautela, una orientación como solsticial cuando los valores de declinación astronómica se aproximen a $\pm 23,5^{\circ} \mathrm{o} \pm 24^{\circ}$, teniendo en cuenta el error considerado para esta magnitud. Determinar el equinoccio astronómico $\left(\delta=0^{\circ}\right)$ exige conocimientos más complejos de astronomía de posición y, a priori, no tendría por qué ser útil o significativo en las cosmologías prehistóricas (Ruggles, 1997). Como alternativa, se propone que sería más sencillo y útil considerar como referencia el día mitad entre los solsticios o, teniendo una referencia en el horizonte, la posición por la que sale o se pone el Sol a medio camino entre los dos solsticios. Esto haría que valores de declinación de pocos minutos o grados puedan tener una explicación equinoccial, pero permite una aproximación a las ideas de las sociedades estudiadas menos sesgada por nuestros conceptos modernos.

La Luna se mueve en un rango de declinación de $\pm 29^{\circ}$, coincidiendo en gran parte con el camino por el que transita el Sol en el horizonte (González-García, 2016), por lo que es muy complicado diferenciar las orientaciones solares de las lunares. No obstante, la hipótesis lunar se ha propuesto para explicar las orientaciones de numerosos megalitos en la península ibérica, como en las antas de siete piedras de Extremadura y el Alentejo (Silva y Pimenta, 2012; Belmonte et al., 2015).

En los casos en los que el horizonte está bloqueado por vegetación a día de hoy, se ha considerado un valor de $0^{\circ}$ a partir de la comparación con la parte del horizonte visible y con modelos digitales de terreno. En concreto se han usado las imágenes del Shuttle Radar Topography Mission (SRTM) de la NASA de $90 \mathrm{~m}$ con la herramienta en línea HeyWhats That (http://www.heywhatsthat.com/). En dichos casos la altura aparece acompañada de un asterisco en la figura 16.

En casos como el de Los Frailes 1, 2 y 3, las tumbas se encuentran en una finca rodeados de vegetación y el estado de deterioro de los monumentos ha obligado a tomar varias medidas en ambos sentidos (10 de dentro a afuera y las mismas de fuera hacia adentro) de las que se ha extraído la mediana, de modo que los datos para estos monumentos han de manejarse con prudencia. 

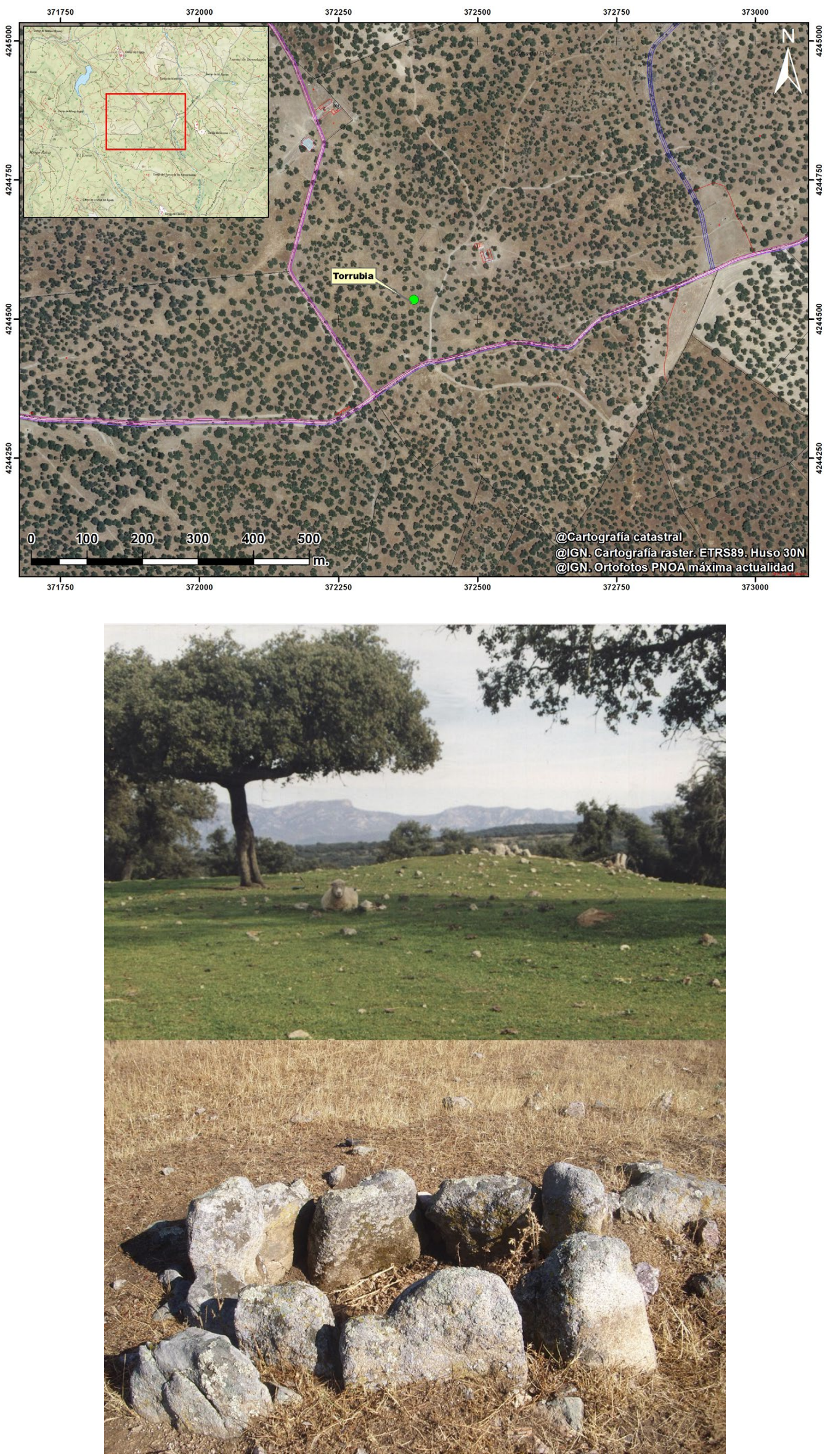

Figura 14: Torrubia. Vista general hacia el norte (arriba) y detalle desde el sur (abajo) 


\begin{tabular}{|l|l|}
\hline Nombre & Torrubia III \\
\hline Término municipal & Cardeña \\
\hline Hoja & $860-141: 10.000$, IECA, Junta de Andalucía \\
\hline Coordenadas XUTM & 372061 \\
\hline Coordenadas YUTM & 4246777 \\
\hline Descripción geográfica: & $\begin{array}{l}\text { Se encuentra unos } 1200 \mathrm{~m} \text { al este del cortijo de Torrubia. Se construyó sobre un } \\
\text { afloramiento rocoso que se eleva unas decenas de metros sobre la planicie adehesada al sur, } \\
\text { siendo reconocible a distancia por su túmulo. }\end{array}$ \\
\hline Morfología: & Meseta. \\
\hline Tipo & Dolmen de corredor con cámara rectangular. Tipo III.1 (Cabrero, 1985). \\
\hline Estructura & $\begin{array}{l}\text { Cámara rectangular de pequeño tamaño, 1,22 m en el eje este-oeste, y 0,87 m en el norte- } \\
\text { sur. Los ortostatos son de pequeño tamaño, tres en la cara oeste y dos en la des tres } \\
\text { de la norte son igualmente de escaso tamaño. }\end{array}$ \\
\hline Depósito ritual & Sin determinar. \\
\hline Atribución cultural & Calcolítico. \\
\hline Estado de conservación & Dañado, aunque son perceptibles la cámara y el corredor. \\
\hline Causas del deterioro & Furtivos. Labores agrícolas. \\
\hline Uso actual del terreno & Pastos/Monte bajo. \\
\hline Observaciones & $\begin{array}{l}\text { La numeración proviene de los dos megalitos citados por Riesgo en la zona. No figura en } \\
\text { sus cuadernos de campo. } \\
\text { Su orientación no es al este, sino al noroeste, Sierra Madrona, lugar con abundantes lugares } \\
\text { con pinturas esquemáticas. }\end{array}$ \\
\hline
\end{tabular}

Figura 15: Ficha del dolmen de Torrubia

\subsection{RESULTADOS: ORIENTACIÓN DE LOS DÓLMENES DE LA comarCa de Los PEDroches}

Aunque somos conscientes de que la muestra de datos es escasa para extraer resultados estadísticamente significativos, los valores presentados son inéditos y pueden servir como complementos al extenso corpus que se ha ido recopilando en las últimas décadas en zonas próximas (Hoskin, 1995b; 2001; González-García y Belmonte, 2010).

Del total de las tumbas, en 5 de ellas la orientación coincide con la salida del Sol en algún momento del año, o la de la Luna. Si bien no se observa preferencia por una época en particular, este resultado responde a los cánones de orientación hallados en la región (Hoskin, 1994; Hoskin, 1995b, Belmonte y Hoskin, 2002), en el resto de España y Portugal (González García, 2009; González García y Belmonte, 2010; Silva, 2013, González García et al., 2017), así como en construcciones coetáneas y posteriores en el Mediterráneo (Belmonte et al., 1998). De hecho, previamente en una muestra de 14 dólmenes en Córdoba se extrajo una orientación media de $83,2^{\circ}$ de acimut, que entra dentro del rango de acimuts en los que sale el Sol a lo largo del año (González-García, 2009: tabla 1). A este valor se aproxima la del dolmen de El Torno (Fig. 16).

En el caso de Las Aguilillas, su estado actual obliga a proceder con cautela en el tratamiento de sus datos. Observando los restos que permanecen y corroborando las medidas tomadas con las memorias de las primeras excavaciones, la entrada de este dolmen miraría al este con un acimut de $90^{\circ}$. Para un horizonte plano, como es el caso, su orientación coincide con la de la salida del Sol en los equinoccios.

Otra orientación llamativa es la de Rongil, pues coincide prácticamente con la salida del Sol en el solsticio de invierno. Aunque de un único caso no puede extraerse un patrón que indique que este momento del ciclo solar era importante, cabe indicar que ésta es una fecha señalada en los calendarios solares de multitud de culturas a lo largo de la historia, ya que el solsticio de invierno marca un punto de inflexión en el año. Durante los días previos y posteriores a los solsticios la posición del Sol a la salida y la puesta no varía, algo que no sucede en otras épocas. Además, a partir del solsticio de invierno los días comienzan a alargarse progresivamente, algo que tradicionalmente ha ido acompañado de rituales de distinta naturaleza, como las Saturnales romanas o la Navidad.

Orientaciones fuera del sector del horizonte por el que sale el Sol aparecen en Torrubia $\left(\delta=28.5^{\circ}\right)$, donde tiene cabida una explicación lunar al estar dentro del rango de coordenadas en el que se mueve este astro y es cercana al valor extremo norte de la salida de la Luna (Lunasticio Mayor Norte, LMN) que era de $\delta=29^{\circ}$ en el segundo y tercer milenios a. C. También es el caso de Los Frailes 1, cuya orientación al suroeste no es a priori compatible con una motivación solar o lunar. En Torrubia otra posible explicación es que la orientación no fuera al Sol naciente, sino al Sol ascendente en el cielo, propuesta sugerida por Michael Hoskin para numerosos dólmenes en Europa occidental, que 


\begin{tabular}{|c|c|c|c|c|}
\hline Estructura & $A\left({ }^{\circ}\right)$ & h $\left(^{\circ}\right)$ & $\varphi\left({ }^{\circ}\right)$ & $\delta\left({ }^{\circ}\right)$ \\
\hline Aguilillas & 90 & 0 & 38,3 & 0 \\
\hline E1 Torno & 84 & $0^{*}$ & 38,2 & 4,3 \\
\hline Frailes 1 & 200,70 & 1 & 38,3 & 46,8 \\
\hline Frailes 2 & 75,65 & $0^{*}$ & 38,3 & $10,3^{*}$ \\
\hline Frailes 3 & 96,65 & $0 *$ & 38,3 & $-5,3^{*}$ \\
\hline Rongil & 119 & 0,5 & 38,2 & $-23,2$ \\
\hline Torrubia & 54,75 & 2,5 & 38,3 & 28,5 \\
\hline
\end{tabular}

Figura 16: Orientación de los dólmenes de la comarca de los Pedroches con los datos de acimut (A), altura del horizonte $(\mathrm{H})$, latitud $(\varphi)$ y declinación astronómica $(\delta)$

clasifica como 'Sun-Climbing' (SC) frente a los que miran al Sol naciente, 'Sun-Rising' (SR) (Hoskin, 2009).

De las 945 tumbas megalíticas medidas en la península ibérica y la parte adyacente a los Pirineos en Francia, este autor encontró que no menos del $96,4 \%$ de los sitios mirarían hacia el Sol naciente o ascendente en el cielo. Sin embargo, también sostuvo que en las regiones que se van alejando de la fachada atlántica el patrón SR se iría relajando, y que en el sur peninsular, donde aparecen grupos de tumbas que presentan orientaciones hacia la salida del Sol, también existen casos anómalos que rompen con esta tendencia (Hoskin, 2009).

A falta de otras fuentes, es muy difícil identificar orientaciones hacia planetas (que también comparten el camino del Sol y la Luna en gran medida) o estrellas por lo que hemos optado por la explicación más sencilla, que en este caso es la solar, aunque no por ello se descarten por completo otros posibles escenarios.

Todos los lugares aquí estudiados presentan orientaciones coherentes con los resultados que obtuvieron Michael Hoskin y su equipo en Andalucía (1995b: fig.1), donde concluyeron que ninguno de los 203 sepulcros megalíticos mira a posiciones septentrionales u occidentales y que sus orientaciones aparecen en un rango de acimut entre $40^{\circ}$ y $204^{\circ}$, siendo este último valor el más occidental y una excepción en la muestra. En el presente caso solo una tumba (Los Frailes 1) presenta una orientación hacia el sector oeste del horizonte con valor $200,70^{\circ}$ y la orientación más septentrional es la del dolmen de Torrubia $\left(54,75^{\circ}\right)$, luego todos se ajustan al patrón predominante en Andalucía hallado previamente.

\section{CONCLUSIONES}

Los elementos megalíticos sometidos a estudio debieron de funcionar como elementos simbólicos para legitimar la apropiación del territorio de Los Pedroches.

La pintura rupestre documentada en El Torno puede estar señalando la relación territorial u homogeneidad de este grupo con el que dominaba Sierra Morena, de forma atestiguada en los actuales municipios de Fuencaliente, Horcajo o Puertollano (provincia de Ciudad Real).
Los resultados obtenidos permiten afirmar que el diseño de la ubicación de los megalitos incluidos en el presente estudio no es casual.

Las orientaciones dadas a estos megalitos resultan consistentes con las orientaciones de otros conjuntos de sepulcros megalíticos en Andalucía y otras regiones de la península ibérica.

Una ampliación de las investigaciones permitiría conocer mejor las nociones que estas sociedades tenían del tiempo, del espacio circundante y de su ritualidad en torno a la muerte.

\section{REFERENCIAS}

Aulló Costilla, M. (1924-1925). Excavaciones arqueológicas en diversos yacimientos sitos en las provincias de Segovia y Córdoba. Memorias de la Junta General de Excavaciones y Antigüedades, 71, 1. Madrid: Junta General de Excavaciones y Antigüedades.

Belmonte, J. A. y Belmonte J. R. (2002). Astronomía y cultura en el megalitismo temprano de la Península Ibérica: los dólmenes de Valencia de Alcántara. En J. A. Belmonte (Ed.). Arqueoastronomía hispana (pp. 99-112). Madrid: Equipo Sirius.

Belmonte, J. A., Esteban, C. y Jiménez López, J. J. (1998). Mediterranean archaeoastronomy and archaeotopography. Journal for the History of Astronomy, 29(23), 7-24. DOI: https://doi.org/10.1177/002182869802902302

Belmonte, J. A. y Hoskin, M. (2002). Reflejo del cosmos: atlas de Arqueoastronomía del Mediterráneo Antiguo. Madrid: Equipo Sirius.

Belmonte, J. A., Tirapicos, L. y Ruggles, C. (2015). Sevenstone antas, Portugal and Spain. En C. Ruggles y M. Cotte (Eds.) Heritage sites of astronomy and archaeoastronomy in the context of the UNESCO World Heritage Convention, Vol. 2 (pp. 17-39). Bognor Regis: Ocarina Books.

Belmonte, J. A., Tirapicos, L. y Ruggles, C. (2017). Sevenstones antas. En C. Ruggles (Ed.). Heritage sites of astronomy and archaeoastronomy in the context of the UNESCO World Heritage Convention II (pp. 17-39). Paris: ICOMOS.

Bermudo Gutiérrez, P. (1972). Notas sobre la evolución de la propiedad rústica privada en Villanueva de Córdoba en el 
último tercio del siglo XVIII y en el siglo XIX. Madrid: Gráficas Martín.

Bueno Ramírez, P., Barroso Bermejo R. M. y Balbin Behrmann, R., de. (2004): Arte megalítico en Andalucía: una propuesta para su valoración global en el ámbito de las grafías de los conjuntos, Mainake, 26, 29-62.

Cabrero, R. (1985). Tipología de los sepulcros calcolíticos en Andalucía Occidental. Huelva Arqueológica, VII, 207-263.

Carbonell Trillo-Figueroa, A. (1927a). Contribución al estudio de la Prehistoria cordobesa. La zona de Villanueva de Córdoba. Boletín de la Real Academia de Córdoba, 19, 85-102.

Carbonell Trillo-Figueroa, A. (1927b). Contribución al estudio de la Prehistoria cordobesa. La zona de Venta de Cardeña. Boletín de la Real Academia de Córdoba, 20, 507-517.

Carbonell Trillo-Figueroa, A. (1928). Contribución al estudio de la Prehistoria cordobesa. La zona de Conquista. Boletín de la Real Academia de Córdoba, 21, 15-26.

Carbonell Trillo-Figueroa, A. (1946). Noticias varias recopiladas en los itinerarios de campo. Cronlechos, dólmenes, cistas, sepulturas, otros monumentos funerarios y restos humanos. Boletín de la Real Academia de Córdoba, 55, 97-106.

Criado Boado, F. (1989). Megalitos, espacio y pensamiento. Trabajos de Prehistoria, 46, 75-98. DOI: https://doi. org/10.3989/tp.1989.v46.i0.588

Da Silva, C. M. (2004). The Spring Full Moon. Journal for the History of Astronomy, 35, 475-478. DOI: https://doi. org/10.1177/002182860403500407

Fernández Rodríguez, M. (2003). Las pinturas rupestres esquemáticas del Valle de Alcudia y Sierra Madrona. Mancomunidad de Municipios del Valle de Alcudia y Sierra Madrona. Ciudad Real: Mancomunidad de municipios del Valle de Alcudia y Sierra Madrona.

García Quintela, M. V. y González-García, A. C. (2009). Arqueoastronomía, antropología y paisaje. Complutum, 20(2), 39-54.

Gavilán Ceballos, B. (2009). Excavación arqueológica puntual en el Dolmen de la Fuente del Corcho (Bélmez, Córdoba). Anuario Arqueológico de Andalucía, 2004(1), 464-470.

Gavilán Ceballos, B., Rodríguez Espinosa, J. y Maura Mijares, R. (2013). Excavación arqueológica en el dolmen de la Fuente del Corcho (Bélmez, Córdoba). Onoba: Revista de Arqueología y Antigüedad, 1, 3-18. DOI: https://doi.org/10.33776/onoba. v0i1.1729

Gavilán Ceballos, B. y Vera Rodríguez, J. C. (2004). Excavación arqueológica IAU de apoyo a la restauración en el dolmen de Las Casas de Don Pedro (Bélmez, Córdoba). Anuario Arqueológico de Andalucía, 3(1), 291-296.

González García, A. C. (2009). Análisis estadístico de las orientaciones de los megalitos en la Península Ibérica. Complutum, 20(2), 177-186.

González-García, A. C. (2016). Lunar extremes, Lunar cycles and the Minor Standstill. Journal of Skyscape Archaeology, 2, 77-84. DOI: https://doi.org/10.1558/jsa.v2i1.30035
González-García, A. C. (2018). Light and shadow effects in megalithic monuments in the Iberian Peninsula. En C. Papadopoulos y H. Moyes (Eds.). The Oxford Handbook of light in Archaeology. Oxford Handbooks Online. DOI: https:// doi.org/10.1093/oxfordhb/9780198788218.013.6

González García, A. C. y Belmonte, J. A. (2010). Statistical Analysis of Megalithic Tomb Orientations in the Iberian Peninsula and Neighbouring Regions. Journal for the History of Astronomy, 41, 225-238. DOI: https://doi. org/10.1177/002182861004100205

González-García, A. C., Criado-Boado, B. y Vilas, B. (2017). Megalithic skyscapes in Galicia. Culture and Cosmos special issue: The marriage of astronomy and culture: theory and method in the study of Cultural Astronomy, 21(1), 87-103. DOI: https://doi.org/10.46472/CC.01221.0211

Gutiérrez Ayuso, A. (2010). Visita al dolmen de Magacela. En A. L. Chamizo Moreno, P. Mora, M. O. Rodríguez Sierra, D. A. Martín Nieto, B. Díaz Díaz y J. Maldonado Escribano (Eds.). III Encuentros de estudios comarcales Vegas Altas, La Serena y La Siberia, dedicados al cuatrocientos aniversario de la expulsión de los moriscos (1610-2010) y al patrimonio de las tres comarcas Magacela - La Coronada (16 y 17 de abril de 2010), edición homenaje a D. Francisco de Córdoba Soriano (pp. 551-557). Magacela - La Coronada: Federación de Asociaciones Culturales de La Siberia, La Serena y las Vegas Altas (SISEVA).

Gutiérrez Escobar, S. y Palomo Palomo, J., (2002). El conocimiento del megalitismo en Los Pedroches. Boletín Informativo de Villanueva de Córdoba, 435-436, 16-19.

Hernández León, E. (1999). El Valle de los Pedroches una comarca limítrofe. Anuario Etnológico de Andalucía, 1995 1997, 125-131.

Hernández León, E. (2005). Fronteras culturales: la construcción de los límites culturales en el valle de los Pedroches. (Tesis doctoral). Universidad de Sevilla. Sevilla. Recuperado de: https://idus.us.es/handle/11441/14926

Hernández León, E. (2014). Acerca de Los Pedroches. PH, 86, 26-33. DOI: https://doi.org/10.33349/2014.0.3516

Hoskin, M. (2001). Tombs, Temples and Their Orientations: A New Perspective on Mediterranean Prehistory. Bognor Regis (UK): Ocarina Books.

Hoskin, M. (2009). Orientations of dolmens of Western Europe. Complutum, 20(2), 165-175.

Hoskin, M., Allan, E. y Gralewski, R. (1994). Studies in Iberian archaeoastronomy: (1) Orientations of the megalithic sepulchres of Almería, Granada and Málaga. Journal for the History of Astronomy, 25, S55-S82. DOI: https://doi. org/10.1177/002182869402501904

Hoskin, M., Allan, E. y Gralewski, R. (1995a). Studies in Iberian archaeoastronomy: (2) Orientations of the tholos tombs of Almería. Journal for the History of Astronomy, 26, 29-40. DOI: https://doi.org/10.1177/002182869502602003

Hoskin, M., Allan, E. y Gralewski, R. (1995b). Studies in Iberian archaeoastronomy: (3) Customs and motives in Andalucía». Journal for the History of Astronomy, 26, 41-48. DOI: https://doi.org/10.1177/002182869502602004 
Ibarra de Dios, F. J., Gutiérrez, S., Palomo Palomo J. y Fernández Durán, W. H. (2003). Historiografía del megalitismo en la provincia de Córdoba: el valle de Los Pedroches. En Andalucía medieval: actas del III Congreso de Historia de Andalucía (Córdoba, 2001), vol. 3: Prehistoria (pp. 142-147). Córdoba: Cajasur, Obra Social y Cultural.

Leisner, G. y Leisner V. (1943). Die Megalithgräber der Iberischen Halbinsel. I. Der Süden. Berlín.

Márquez Triguero, E. (1997). Las pinturas esquemáticas del dolmen del Torno (Villanueva de Córdoba). En XV Congreso Nacional de Cronistas españoles y XXV Reunión Anual de Cronistas Cordobese (pp. 335-340). Córdoba: Diputación de Córdoba.

Márquez Triguero, E. (2001). El Valle de los Pedroches y su riqueza arqueológica. Crónica de Córdoba y sus pueblos, $6,315-322$

Marfil Lopera, C. (1997a). Megalitismo en el Valle de los Pedroches (Córdoba): Estado actual del conocimiento. En P. Bueno Ramírez y R. de Balbín Behrmann (Coords.). II Congreso de Arqueología Peninsular (Zamora, 24-27 septiembre 1996), vol. 2 (pp. 257-262). Zamora: Fundación Rei Afonso Henriques.

Marfil Lopera, C. (1997b). Aproximación al Calcolítico en el Valle de los Pedroches (Córdoba). Una revisión del fenómeno megalítico de la zona. Cuadernos del Gallo, 19, 19-168.

Martín de la Cruz J. C. y Gutiérrez Escobar, S. (Coords.). (2007). Minguillo IV (Villanueva de Córdoba) en el contexto megalítico de Andalucía. Córdoba: Universidad de Córdoba - Ayuntamiento de Villanueva de Córdoba.

Martínez Boloix, J. (2002). El dolmen de las casas de Don Pedro en Sierra Palacios (Belmez, Córdoba): estudio analítico y metalúrgico de su material de cobre y su incorporación a la serie campaniforme provincial. Córdoba: Universidad de Córdoba.

Moreno Rosa, A. y Carmona Ávila, R. (1992). Megalitismo en la Subbética cordobesa: el dolmen de la Dehesa de La Lastra (Sierra Alcaide). Antiquitas, 3, 31-35.

Muñiz Jaén, I., Moreno Rosa, A. y Carmona Ávila, R. (1993). El dolmen de la Dehesa de La Lastra: resultados de una nueva intervención arqueológica de emergencia. Antiquitas, 4, 24-37.

Murillo Redondo, J. F. (1986). Eneolítico y Edad del Bronce en el Norte de la provincia de Córdoba (Memoria de Licenciatura inédita). Universidad de Córdoba. Córdoba.

Murillo Redondo, J. F. (1988). Ídolos calcolíticos procedentes del sepulcro megalítico del Atalayón, Villanueva de Córdoba. Ariadna, 5, 81-93.

Ocaña Torrejón, J. (1967). Túmulos en los Pedroches. Boletín de la Real Academia de Córdoba, 87, 165-181.

Polcaro, A. y Polcaro, V. F. (2006). Early Bronze Age dolmens in Jordan and their orientations. Mediterranean Archaeology and Archaeometry, 6(3), 169-174.

Riesgo Ordóñez, A. (1934a). Entomología forestal y Arqueología. El Auxiliar de la Ingeniería y Arquitectura, $315,150-153$.

Riesgo Ordóñez, A. (1934b). Entomología forestal y Arqueología. El Auxiliar de la Ingeniería y Arquitectura, 316, 168-171.
Riesgo Ordóñez, A. (1934c). Entomología forestal y Arqueología. El Auxiliar de la Ingeniería y Arquitectura, 317, 181-184.

Riesgo Ordóñez, A. (1934d). Entomología forestal y Arqueología. El Auxiliar de la Ingeniería y Arquitectura, 318, 199-200.

Riesgo Ordóñez, A. (1934e). Entomología forestal y Arqueología. El Auxiliar de la Ingeniería y Arquitectura, Madrid, 319, 217-218.

Riesgo Ordóñez, A. (1934f). Entomología forestal y Arqueología. El Auxiliar de la Ingeniería y Arquitectura, 320, 233-234.

Riesgo Ordóñez, A. (1936a). Los primitivos habitantes del Valle de los Pedroches (Córdoba). El Auxiliar de la Ingeniería y Arquitectura, Madrid, 354, 8-12.

Riesgo Ordóñez, A. (1936b). Los primitivos habitantes del Valle de los Pedroches (Córdoba). El Auxiliar de la Ingeniería y Arquitectura, 355, 30-33.

Riesgo Ordóñez, A. (1943). Libreta de Campo. (Original manuscrito). Córdoba: Museo de Córdoba.

Riesgo Ordóñez, A. (1948). Arqueología del Valle de los Pedroches (Córdoba). Actas y Memorias de la Sociedad Española de Antropología, Etnología y Prehistoria, XXIII(III), 76-82.

Riesgo Ordóñez, A. (1954). Libreta de Campo. (Original manuscrito). Córdoba: Museo de Córdoba.

Ruggles, C. (2010). Later prehistoric Europe. En C. Ruggles y M. Cotte (Eds). Heritage Sites of Astronomy and Archaeoastronomy in the Context of the UNESCO World Heritage Convention: a Thematic Study (pp. 28-35). Paris: ICOMOS-IAU.

Santos Jener, S. (2007). Dolmen con insculturas en arroyo de las Sileras (Córdoba, Espejo). Crónica del IV Congreso Arqueológico del Sudeste Español (Murcia,1948) (pp. 142150). Murcia.

Silva, F. (2013). Landscape and Astronomy in Megalithic Portugal: the Carregal do Sal Nucleus and Star Mountain Range. Papers from the Institute of Archaeology, 22, 99-114. DOI: https://doi.org/10.5334/pia.405

Silva, F. y Pimenta, F. (2012). The crossover of the sun and the moon. Journal for the history of astronomy, 43, 191-208. DOI: https://doi.org/10.1177/002182861204300204

Valle Buenestado, B. (1978). Villanueva de Córdoba: estudio geográfico de un municipio de Los Pedroches. Córdoba: Diputación Provincial de Córdoba.

Valle Buenestado, B. (1983). Estudio geográfico de la Comarca de los Pedroches. (Tesis doctoral inédita). Universidad de Córdoba. Córdoba.

Valle Buenestado, B. (2016). La Sierra Morena Cordobesa: naturaleza, génesis del paisaje y patrimonio ambiental. $\mathrm{PH}, 90$, 30-47. DOI: https://doi.org/10.33349/2016.0.3838

VV. AA. (2014). El valle de los Pedroches. PH, 86 (monográfico), 24-87. 